Universidad de Lima

Escuela de Posgrado

Maestría en Tributación y Política Fiscal

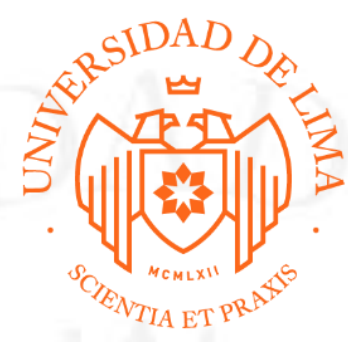

\title{
CRÍTICA A LOS EFECTOS TRIBUTARIOS DE LA PROVISIÓN DE COBRANZA DUDOSA EN LAS ENTIDADES FINANCIERAS
}

Trabajo de investigación para optar el Grado Académico de Maestro en Tributación y Política Fiscal

\section{Katia Magaly Alva Vilcherres \\ Código 20162692 \\ Nilda Selena Ramírez Villanueva \\ Código 19870629}

Asesor:

Beatriz De la Vega

Lima - Perú

Mayo del 2019 


\section{CRÍTICA A LOS EFECTOS TRIBUTARIOS DE LA PROVISIÓN DE COBRANZA DUDOSA EN LAS ENTIDADES FINANCIERAS}

\section{CRITICISM OF THE TAX EFFECTS OF THE PROVISION OF DOUBTFUL COLLECTION IN FINANCIAL INSTITUTIONS}




\section{TABLA DE CONTENIDO}

\section{INTRODUCCIÓN}

\section{CAPÍTULO I: TRATAMIENTO ECONÓMICO Y FINANCIERO DE LA}

COBRANZA DUDOSA EN EL SECTOR FINANCIERO .....................................3

1.1. Principios y recomendaciones del BASILEA. Implementación de sus estándares en el Perú...................................................................................

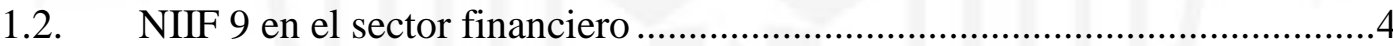

1.3. Normativa de la Superintendencia de Banca y Seguros y Administración de

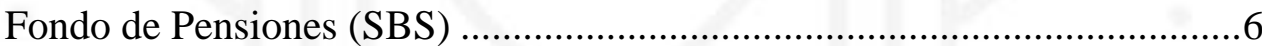

1.3.1. El sector financiero y la regulación de la SBS .......................................

1.3.2. Normativa de la SBS sobre provisión de cobranza dudosa. Ámbito de

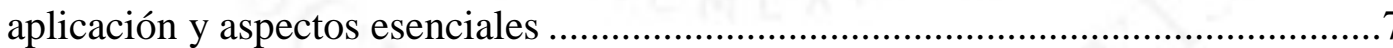

\section{CAPÍTULO II: TRATAMIENTO TRIBUTARIO DE LA PROVISIÓN DE} COBRANZA DUDOSA ...................................................................................11

2.1. Régimen general aplicable a la cobranza dudosa en la Ley del Impuesto a la

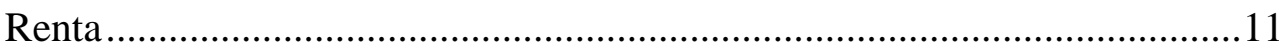

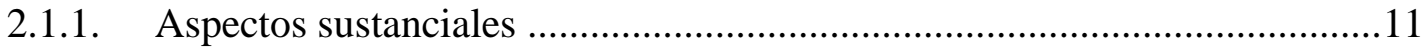

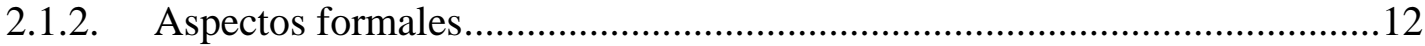

2.2. Régimen especial aplicable a la cobranza dudosa para las empresas del sector

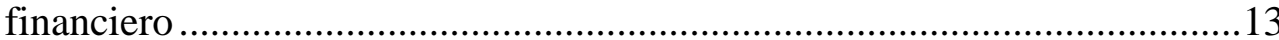

2.3. Regulación de la cobranza dudosa en la legislación comparada...................14 


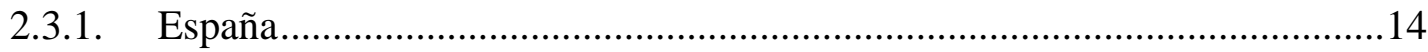

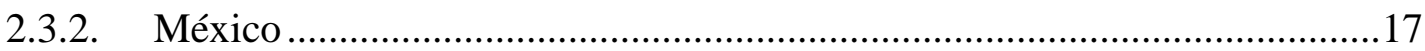

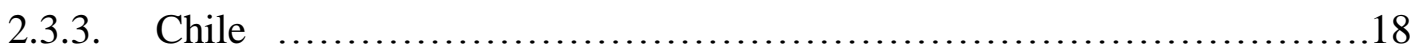

\section{CAPÍTULO III: PRINCIPIOS CONSTITUCIONALES TRIBUTARIOS}

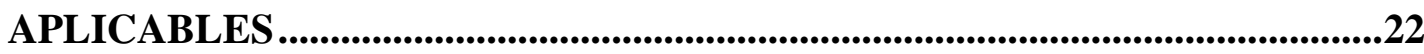

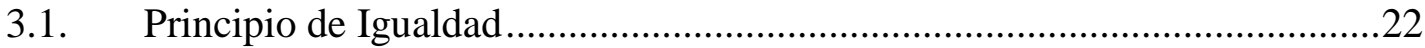

3.1.1. Dimensiones de la Igualdad: formal y material ..........................................22

3.1.2. El principio de la Igualdad en la Jurisprudencia...........................................24

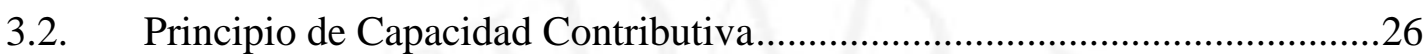

3.2.1. El principio de capacidad contributiva en la Jurisprudencia .........................27

CAPITULO IV: PROVISIÓN DE COBRANZA DUDOSA. COMPARACIÓN DEL TRATAMIENTO TRIBUTARIO ENTRE EL SECTOR FINANCIERO Y OTROS SECTORES ECONÓMICOS

4.1. Razones que validan el procedimiento establecido por la SBS a la provisión de cobranza dudosa de instituciones financieras . .29

4.2. Argumentos en contra del tratamiento diferenciado........................................31

4.2.1. Evaluación de cartera: alineamiento y conglomerado único ..........................31

4.2.2. Intereses en suspenso, ¿percibido o devengado? ........................................... 31

4.2.3. Castigo de cuentas provisionadas ...............................................................34

4.2.4. Comparación con empresa de servicio masivo................................................34

4.3. Nuestra posición ........................................................................................

CONCLUSIONES ….............................................................................................43

REFERENCIAS..................................................................................................45

BIBLIOGRAFÍA _................................................................................................51

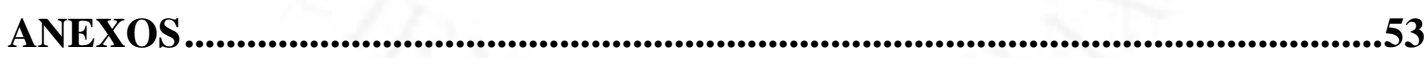




\section{ÍNDICE DE ANEXOS}

Anexo 1: Ingreso tributario anual recaudado por la SUNAT .

.54 


\section{RESUMEN}

En este estudio se analiza si existen razones que sustenten el tratamiento tributario aplicable a la provisión de cobranza dudosa en Instituciones financieras. En la investigación se determina que el tratamiento tributario diferenciado para el sector financiero, respecto a los otros sectores económicos, se fundamenta y justifica en razones económicas, dado que existe una relación directa entre el crecimiento del PBI y el desarrollo de dicho sector. El Estado peruano orienta el desarrollo del país, por ello, en aras de mantener el equilibrio del mercado y el crecimiento económico, permite las deducciones tributarias de las provisiones exigidas por la Superintendencia de Banca, Seguros y AFP (SBS).

Palabras clave: Cobranza dudosa, Sector financiero, SBS, PBI 


\begin{abstract}
This study analyzes whether there are reasons that support the tax treatment applicable to the provision of doubtful collection in financial institutions. In the investigation it is determined that the differentiated tax treatment for the financial sector, with respect to the other economic sectors, is based and justified in economic reasons, given that there is a direct relationship between the growth of the GDP and the development of said sector. The Peruvian State guides the development of the country, therefore, in order to maintain market balance and economic growth, it allows tax deductions for the provisions required by the Superintendency of Banking, Insurance and AFP (SBS).
\end{abstract}

Keywords: Doubtful collection, Financial sector, SBS, PBI 


\section{INTRODUCCIÓN}

El presente proyecto de tesis, tiene por objetivo analizar si existen razones económicas que sustenten el tratamiento tributario diferenciado aplicable a la provisión de cobranza dudosa de instituciones financieras y sus efectos tributarios en el Perú.

Hemos observado que el tratamiento tributario especial al sector financiero en relación a otros sectores económicos y la regulación por la Superintendencia de Banca y Seguros conlleva, entre otros, a que las entidades financieras registren una provisión financiera por incobrable mayor a la que correspondería si solo se analizara la relación directa “deudor - acreedor", los intereses generados por los créditos provisionados, se reconocen como ingresos en función al principio del percibido y no del devengado y los castigos de cobranza dudosa se aceptan tributariamente en la medida que la Superintendencia de Banca y Seguros [SBS] emita una certificación de irrecuperabilidad de la deuda, no es necesario que se demuestre judicialmente dicha situación.

A grandes rasgos podemos decir que las instituciones financieras captan los ahorros de las familias, empresas, sector público y entidades del sector externo, que tienen excedentes y los colocan a otras familias, empresas, entidades del sector público o del sector externo que necesitan dinero para invertir o gastarlo; al respecto, la tarea del ente regulador es proteger a los ahorristas, y aquí nuestra crítica, ¿ello justifica ese tratamiento tributario diferenciado? o ¿es posible que el tratamiento tributario se aleje de las normas contables que regula la SBS?

En el capítulo I, tratamiento económico y financiero de la cobranza dudosa en el sector financiero, se presentará los principios y normas que rigen el tratamiento financiero del sector, las exigencias de Basilea o de organismos internacionales, las nuevas exigencias contables de las NIIF y la normatividad peruana.

En el capítulo II, tratamiento tributario de la provisión de cobranza dudosa, se verá el tratamiento tributario aplicable en la Ley del Impuesto a la Renta respecto a los otros sectores económicos, el tratamiento tributario a las instituciones financieras y la regulación de cobranza dudosa en la legislación comparada: España, México y Chile. 
En el capítulo III, se analizan los principios constitucionales tributarios aplicables en nuestro país, evaluaremos si estamos frente a una situación de discriminación o de diferenciación frente a los otros sectores económicos.

En el capítulo IV se analiza el tratamiento tributario en el Perú para la Provisión de cobranza dudosa en las instituciones financieras en comparación con los otros sectores económicos, y las razones de aceptar tributariamente el procedimiento establecido por la SBS para la provisión de cobranza dudosa, el tratamiento de los "intereses en suspenso y el castigo de cuentas provisionadas"; así mismo se compara mediante un caso real, las exigencias tributarias para la deducibilidad de la provisión de cobranza dudosa en una empresa con una cartera de clientes masiva frente a las exigencias para las entidades financieras, y finalmente nuestra posición del tema de investigación. 


\section{CAPÍTULO I: TRATAMIENTO ECONÓMICO Y FINANCIERO DE LA COBRANZA DUDOSA EN EL SECTOR FINANCIERO}

\subsection{Principios y recomendaciones del BASILEA. Implementación de sus estándares en el Perú}

Para comprender el rol del Comité de Basilea, es necesario remontarnos a su origen.

En el año 1974, el banco central alemán ordenó el cierre del Bankhaus Hersttat debido a sus importantes pérdidas derivadas de sus operaciones en moneda extranjera. Muchas operaciones internacionales no se realizaron porque el banco Chase Manhattan, no cumplió con las órdenes de pago y cheques, originando una crisis financiera internacional. Ante esta situación, fue necesario establecer nuevos parámetros de colaboración e intercambio de información entre los bancos centrales así como intervenir en los mercados, se establece el Comité en supervisión bancaria conformado por los supervisores bancarios de los países miembros del G-10.

De acuerdo a Ustáriz González (junio 2003), la finalidad del Comité de Basilea, es dar recomendaciones para minimizar los riesgos a los que se exponen las instituciones financieras. Entre los que ha desarrollado la supervisión como elemento fortalecedor y que promueve la eficiencia y estabilidad macroeconómica de un país. (p. 433).

Las recomendaciones del Comité de Basilea, se centran en cubrir los riesgos que afronta toda institución financiera y el principal es el riesgo crediticio.

El riesgo crediticio, se evalúa desde la cartera que constituye el principal activo de los bancos, para ello se clasifica la cartera según el tipo de deudor en cuatro categorías ponderadas $(0 \%, 20 \%, 50 \%, 100 \%)$, como señalan De Miguel Domínguez, Miranda Torrado, Pallas Gonzales Y Peraza Fandiño (2008, p. 4).

El Comité de Basilea no tiene ningún poder legal en los diferentes países, sin embargo, el hecho de que los países, en primer lugar, los miembros del G-10, incluyan en sus legislaciones las recomendaciones del Comité, le han otorgado gran influencia internacional. 
En el Perú, la implementación de las recomendaciones de Basilea, toma tiempo, tanto, que al momento en que se logra una implementación adecuada, surgen nuevas recomendaciones en Basilea. Así ocurrió, tal como lo señala Izu (2018) mientras la Superintendencia de Banca Seguros y AFP [SBS] logró una adopción adecuada de Basilea II con el Decreto Legislativo $N^{\circ} 1028$, ya en el 2010 el estándar internacional había cambiado con Basilea III. (p. 2).

En el 2016, mediante la Resolución SBS N 975-2016 de la Superintendencia de Banca, Seguros y AFP [SBS] (2016), nos aproximamos a los requerimientos de Basilea III, sin embargo, en Europa ya se hablaba de Basilea IV o una revisión de Basilea III.

Hoy, la finalidad de la creación del Comité de Basilea, recobra relevancia ante la globalización, al respecto el Centro Interamericano de Administraciones Tributarias [CIAT] (2017) destaca que la crisis financiera internacional iniciada en Estados Unidos, impactó en todos los países, por lo que sus recomendaciones incluyen requerimientos más exigentes entre las que figuran las referidas a los créditos, provisiones y garantías.

Las exigencias de Basilea IV, se centran justamente en la metodología que deben utilizar los bancos para calcular el riesgo, ya sea crediticio, operacional, de mercado y las grandes exposiciones.

En lo que concierne al riesgo crediticio, se limitan la metodología interna de cada banco para la estimación de la provisión por insolvencia (provisión por incobrabilidad) de tal forma que las provisiones se realicen en función a las pérdidas esperadas y no a las pérdidas incurridas, asemejándose más al modelo estándar.

En el Perú, solo existe un modelo estándar para la provisión por incobrabilidad, por lo que podría pensarse que las nuevas exigencias no implicarían cambios en la normativa actual de la SBS, sin embargo, si deberán evaluarse los criterios sobre los cuales se fundamenta la nueva propuesta de Basilea.

\subsection{NIIF 9 en el sector financiero}

La NIIF 9 Instrumentos Financieros, que sustituye a la NIC 39 a partir del 01 de enero del 2018, incluye la clasificación de activos y pasivos financieros, metodología del deterioro del valor y contabilidad de coberturas. 
En lo relacionado a nuestro tema, debemos centrarnos en el reconocimiento del deterioro de valor de los activos financieros, cuentas por cobrar y créditos.

Se plantea que la morosidad, entendiéndose como incumplimientos reales, no es el único elemento para medir el riesgo crediticio, y en todo caso es una medida del pasado más no permite prever y dar información confiable a los stakeholders, ante ello, la NIIF 9 propone tres métodos de medición, según Gutiérrez, Osorio y Romero-Meza (2018):

(a) un importe de probabilidad ponderada no sesgado que se determina mediante la evaluación de un rango de resultados posibles;

(b) el valor temporal del dinero; y

(c) la información razonable y sustentable que está disponible sin costo o esfuerzo desproporcionado en la fecha de presentación sobre sucesos pasados, condiciones actuales y pronósticos de condiciones económicas futuras. (p. 6).

Así, la NIIF 9 establece un modelo de medición de pérdidas crediticias basado en las pérdidas esperadas y no solo incurridas, he ahí el reto y la dificultad que afrontan las entidades financieras considerando que estimar la pérdida de crédito esperada es cuestión de juicio que implica entre otros:

- $\quad$ El conocimiento que se tenga del cliente.

- $\quad$ El tamaño y complejidad de la entidad.

- Los factores micro y macroeconómicos.

- $\quad$ La calidad, disponibilidad y oportunidad de la información.

Por lo que es evidente que la estimación de la pérdida implicaría sesgo en la estimación, más aún si es posible que cada entidad establezca su propia metodología de estimación de provisión.

Habiendo señalado lo que propone la NIIF 9, nos preguntamos si en el Perú se habrían considerado ya algunos criterios que hacen que la provisión de cobranza dudosa exigida por la SBS no se base únicamente en la morosidad sino que incluye algunos parámetros que determinan que la provisión tengan algunos rasgos que permitan calificarla como pérdida esperada y no solo incurrida; nos referimos al alineamiento con la calificación en otras entidades financieras o el tener en cuenta el grupo económico al que pertenece el deudor o el comportamiento de las otras empresas del grupo económico al que pertenece. 
Cabe indicar que la NIIF 9 aun no es aplicada de manera obligatoria en las entidades financieras en el Perú, dado que la SBS no ha modificado el Manual de Contabilidad para Empresas del Sistema Financiero al respecto.

\subsection{Normativa de la Superintendencia de Banca y Seguros y Administración de Fondo de Pensiones (SBS)}

Para comprender la importancia de las instituciones financieras, es necesario señalar el rol del sistema financiero en la economía de los países.

En este sentido, son dos los elementos que permiten el crecimiento y desarrollo económico: el capital humano y el capital físico (Krugma y Wells, 2014), respecto al capital físico es que cobra importancia el sistema financiero, ya que permite financiar la inversión e inducir al ahorro.

Las instituciones financieras captan el ahorro de las familias, empresas, sector público y sector externo y los prestan a otros usuarios para invertir o consumir; sin embargo, no prestan todo lo que captan sino que deben mantener activos líquidos que le permitan devolver a los ahorristas los montos que soliciten. Aunado a ello, se busca proteger a los ahorristas y asegurar el recupero de los préstamos (Porporatto, 2013, p. 5).

Entre las medidas adoptadas encontramos el seguro de depósitos, requerimientos de capital y reservas reglamentarias.

Si bien las recomendaciones de Basilea consideran lo mencionado en el párrafo anterior, también incluye la necesidad de supervisión, concepto que ha sido reforzado en Basilea III a raíz de la crisis del 2008.

En nuestro país la labor de supervisión recae en la Superintendencia de Banca y Seguros (SBS), quien, a través de sus circulares y resoluciones, regula el actuar de las instituciones financieras.

Hemos descrito la importancia económica de las instituciones financieras, la cuestión es si ello justifica que tributariamente, sobre todo en la Ley de Impuesto a la Renta, se plasmen tratamientos diferentes al sector financiero respecto de otros sectores.

¿Las razones serán de índole de política económica y fiscal? Interrogante que responderemos al final del capítulo IV. 


\subsubsection{El sector financiero y la regulación de la SBS}

La Ley $N^{\circ} 26702$ (2014) de la SBS, establece en sus artículos 345 y 347, que su objetivo es proteger los intereses del público y por ello ejerce control y supervisión de las empresas del sistema financiero, y como parte de su función preventiva ha regulado los criterios para la evaluación del riesgo crediticio.

\subsubsection{Normativa de la SBS sobre provisión de cobranza dudosa. Ámbito de aplicación y aspectos esenciales}

Mediante la resolución de la SBS (2008) N 11356-2008, la Superintendencia de Banca, Seguros y AFP señaló que para evaluar la cartera de créditos, debe considerarse factores relevantes para determinar la capacidad de pago de la deuda, entre ellos situación financiera, patrimonio neto y capacidad de pago, siendo que este último abarca el análisis del flujo de caja y los antecedentes del deudor.

Asimismo, uno de los medios utilizados para atenuar los riesgos de los ahorristas, es la constitución de provisiones por incobrabilidad.

Las provisiones exigidas por la SBS pueden ser genéricas o específicas. A continuación, explicaremos los rasgos más resaltantes de la provisión de incobrabilidad exigida y que luego analizaremos desde el punto de vista tributario.

Categorías de los créditos

La SBS (2008) clasifica a los deudores en cinco categorías:
a) Categoría Normal
b) Categoría con Problemas Potenciales
c) Categoría Deficiente
d) Categoría Dudoso
e) Categoría Pérdida (p. 17).

Los parámetros para la evaluación de los deudores se especifican por categoría y por tipo de crédito y a cada una de ellas corresponde un porcentaje de provisión por incobrabilidad. 
De manera general, la evaluación de un solicitante, minoristas o no, debe incluir:
a) Su entorno económico
b) Capacidad de hacer frente a sus obligaciones ante variaciones cambiarias, comerciales, políticas o regulatorias
c) Tipo de garantías que respalda el crédito
d) La calidad de dirección de la empresa
e) Las clasificaciones asignadas por las demás empresas del sistema financiero. (SBS, 2008, p. 14).

Además, la evaluación se realiza en el entorno de pertenecer a un grupo económico, conglomerado financiero o en base a supuesto de riesgo único.

La Ley $\mathrm{N}^{\circ} 26702$ (1996) ha definido en su artículo 203 que

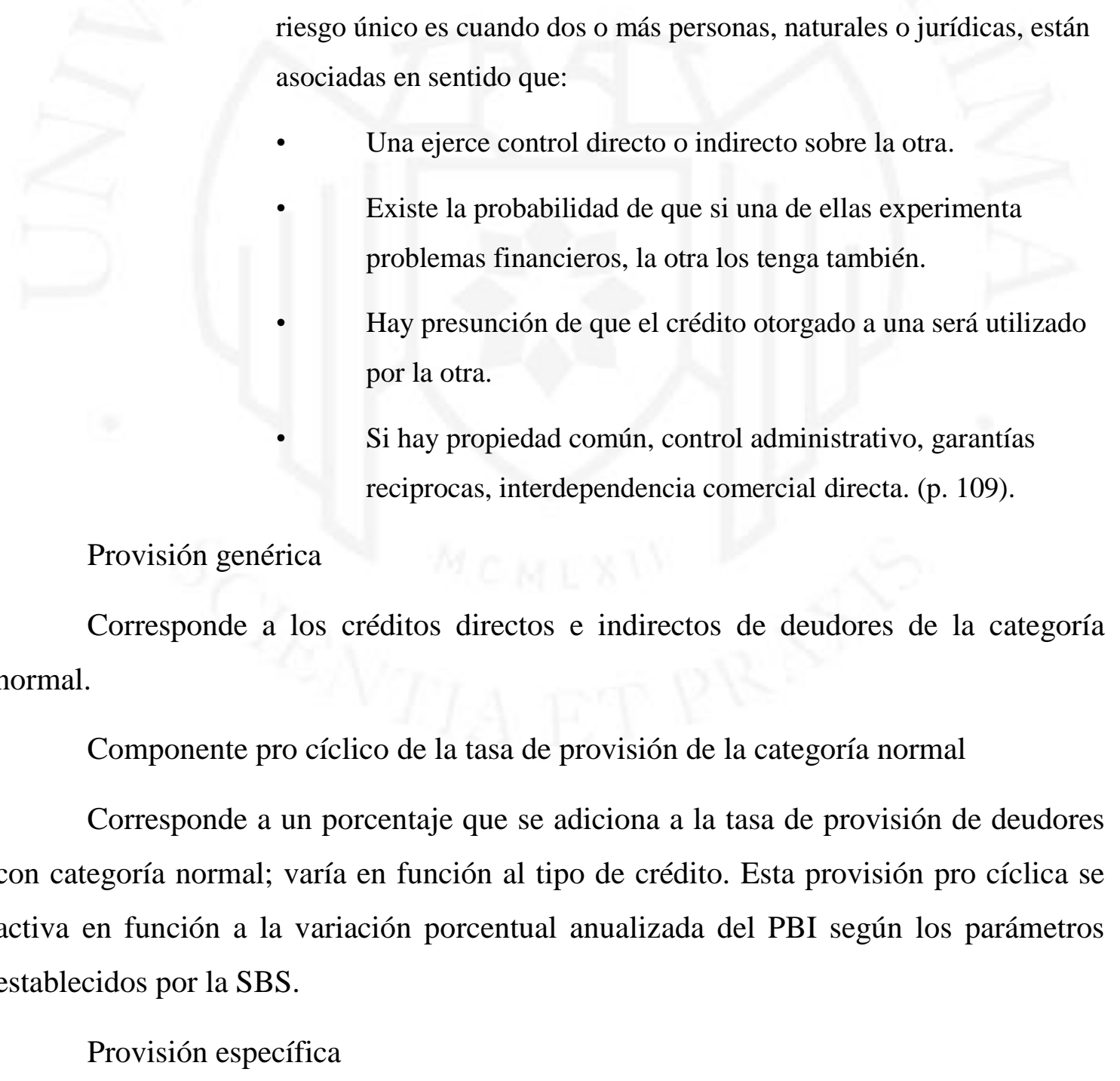


Corresponde a los créditos directos e indirectos de deudores de mayor riesgo a la categoría normal.

\section{Alineamiento}

Una de las características de la evaluación de deudores, es lo que se conoce como alineamiento, que conlleva a clasificar al deudor a la categoría de mayor riesgo fijada en cualquiera de las entidades del sistema financiero, siempre que la acreencia en esta última represente un mínimo del $20 \%$ del total adeudado en el sistema financiero, cabe indicar que se permite discrepar en un nivel de categoría.

Respecto a los deudores minoristas, el procedimiento de alineamiento considera otros límites, sin embargo, no ahondaremos en ello ya que lo primordial en el alineamiento es el hecho de la obligación de considerar la categoría más riesgosa del sistema financiero en la evaluación de la cartera.

Considerando el rol y la importancia del sector financiero en la economía del país, que se mencionó en el acápite 1.3, el

sistema bancario refleja en gran medida la salud de la economía. De hecho, las fluctuaciones en las condiciones del sector real de la economía, particularmente en el sector empresarial, tienen un impacto inmediato en la solidez del sistema bancario a través de sus efectos sobre la calidad del portafolio de créditos, que finalmente afectan los niveles de capital bancario y reservas. (Muñoz, 1999, p. 107).

Lo mencionado, explica la interrelación que existe entre el desarrollo económico y el comportamiento de la cartera crediticia de las entidades financieras, al punto de que la falta de pago de los clientes afecta la solvencia bancaria.

En esta línea, Aparicio y Moreno (2011) señalan:

Existen algunos estudios que han analizado cuáles son los factores macroeconómicos que impactan sobre la calidad de la cartera crediticia en el Perú y en otros países de la región. La gran mayoría de estos estudios han considerado indicadores basados en la cartera atrasada como proxy de la calidad de la cartera crediticia bancaria. (p. 2).

Por ello, la clasificación de la cartera crediticia responde en principio a la morosidad del deudor, sin embargo los parámetros de alineamiento, de pertenencia a un grupo económico, entre otros, que también son considerados en la evaluación, 
¿responden realmente al riesgo crediticio? ¿la exigencia financiera supone su aceptación desde el punto de vista tributario? Interrogantes que nos responderemos en el Capítulo IV de la presente tesis. 


\section{CAPÍTULO II: TRATAMIENTO TRIBUTARIO DE LA PROVISIÓN DE COBRANZA DUDOSA}

\subsection{Régimen general aplicable a la cobranza dudosa en la Ley del Impuesto a la Renta}

\subsubsection{Aspectos sustanciales}

El tratamiento de la deducción de la provisión de cobranza dudosa se encuentra regulada en la Ley del Impuesto a la Renta, a través del Decreto Supremo N 179-2004 (2004), y en su Reglamento para todos los contribuyentes, a través del Decreto Supremo $\mathrm{N}^{\circ} 122$ 94-EF (1994), con excepción del Sector Financiero y Bancario.

El inciso i) del artículo 37 de la Ley del Impuesto a la Renta (DS N 179-2004EF, 2004), aplicable a los sectores distintos al financiero, señala que son deducibles "los castigos por deudas incobrables y las provisiones equitativas por el mismo concepto, siempre que se determinen las cuentas a las que corresponden."

\section{Así mismo,}

no se reconoce el carácter de incobrable de las deudas entre partes vinculadas, las afianzadas por empresas del sistema financiero, las garantizadas mediante derechos reales de garantía, depósitos dinerarios o compra venta con reserva de propiedad y las que hayan sido renovadas o prorrogadas. (DS $\mathrm{N}^{\circ} 179-2004-$ EF, 2004, art. 37, ínciso i)

$\mathrm{Al}$ respecto, el artículo 21 inciso f) del reglamento de la Ley del Impuesto a la Renta (DS N ${ }^{\circ}$ 122-94-EF, 1994), señala que para efectuar la provisión de deudas incobrables se debe tener en cuenta:

1) Que "el carácter de incobrable debe verificarse en el momento en que se efectúa la provisión contable"; es decir, la norma obliga a que la empresa efectúe su contabilización cuando sucede tal hecho objetivo; es decir que el deudor no puede pagar o su comportamiento indica que la deuda es incobrable.

2) "La deuda esté vencida". 
3) Se demuestren "dificultades financieras del deudor [...] o se demuestre su morosidad o hayan transcurrido doce meses desde el vencimiento de la obligación".

4) Se debe identificar el derecho de cobro por documento y cliente, cabe indicar que existe jurisprudencia al respecto; por ejemplo en "la RTF $\mathrm{N}^{\circ}$ 2492-3-2002 de fecha 10.05.2002 determina que para las provisiones de cobranza dudosa [...], el contribuyente debe acreditar el origen de las deudas." (Mundo Contable, 12 junio de 2012, párr. 14).

De lo anterior se desprende que la norma no precisa con qué documentos probatorios podría efectuar la provisión para encontrarse inmerso en los requisitos otorgados por la Ley y su Reglamento; sin embargo, en la práctica se verifica que la procedencia de la provisión debe ser evaluada en cada caso por cliente.

Independientemente de lo manifestado en el párrafo anterior, tenemos en el Perú, para sectores distintos al financiero, las normas tributarias tienen sus propias exigencias para la deducibilidad de la provisión de cobranza dudosa.

\subsubsection{Aspectos formales}

Según Alva Matteucci (15 de mayo de 2017), las normas tributarias exigen "que la provisión de cobranza dudosa al cierre de cada ejercicio gravable figure en el Libro de Inventarios y Balances en forma discriminada" (punto 6.3); en este punto se obliga al contribuyente a efectuar y presentar de manera discriminada y no de manera genérica, cada una de las operaciones y por cliente que determinan el cálculo de las provisiones.

Al respecto tenemos jurisprudencia, tal como la RTF No 590-4-2002 que señala que "el registro discriminado de la provisión debe efectuarse en el propio Libro de Inventarios y Balances y no en documentos anexos a los mismos." (Alva Matteucci, 15 de mayo de 2017, punto 5 - c).

Asimismo, tenemos la RTF No 06985-3-2007 que

confirmó la posición de la Administración Tributaria frente al contribuyente en cuanto al reparo por gastos por provisión de cobranza dudosa debido a que la recurrente no ha detallado los importes que contiene dicha cuenta. Se indica que el listado en hoja suelta presentado por la recurrente fue legalizado con 
posterioridad a la fecha de notificación del requerimiento, no habiendo presentado la recurrente documentación adicional que sustentara la fehaciencia y pre existencia de los hechos que el anexo detalla, esto es, documentación que acredite que al cierre del ejercicio 2001, la provisión de cobranza dudosa se encontraba debidamente discriminada. (Alva Matteucci, 15 de mayo de 2017, punto 5 - c).

LA RTF $N^{\circ}$ 2116-5-2006 de fecha 25 de Abril de 2006, señaló que el contribuyente solo presentó el Libro de Inventarios y Balance en donde se detallaba los comprobantes de pago que originaban la deuda, sin embargo no se acreditó con documentación la antigüedad y origen de las deudas por las cuales habría provisionado.

Se demuestra con lo anterior que no basta cumplir el requisito formal de presentar el Libro de Inventario y Balance y anexos de ser el caso; sino que el contribuyente debe acreditar la deuda provisionada en base a los requisitos de la norma, aspectos sustanciales, por tanto, no son aceptables provisiones efectuadas considerando estimaciones o porcentajes sobre las deudas por cliente.

\subsection{Régimen especial aplicable a la cobranza dudosa para las empresas del sector}

\section{financiero}

Se verifica en la normatividad tributaria que la deducción de las cuentas de cobranza dudosa de clientes de empresas del Sector Financiero, tiene un tratamiento especial ventajosa y diferenciada del resto de contribuyentes; así el inciso h) del artículo 37 del Decreto Supremo N 179-2004 (2004) señala que "serán deducibles las provisiones que, habiendo sido ordenadas por la Superintendencia de Banca y Seguros, sean autorizadas por el Ministerio de Economía y Finanzas, previa opinión técnica de la Superintendencia Nacional de Administración Tributaria - SUNAT," y que se trate de provisiones:

- específicas.

- "que no formen parte del patrimonio efectivo".

- "vinculadas exclusivamente a riesgos de crédito, clasificados en las categorías de problemas potenciales, deficiente, dudoso y pérdida."

Como vemos, la norma tributaria se remite a aceptar como deducible las provisiones que exige el ente supervisor (SBS), quien fundamenta sus exigencias en criterios financieros y de protección a los ahorristas, objetivos distintos a los tributarios. 
Cabe indicar que si bien del Reglamento se desprende que para la deducibilidad de las provisiones exigidas por la SBS es necesaria la autorización de las mismas por el "Ministerio de Economía y Finanzas mediante resolución Ministerial” previa opinión técnica de la SUNAT (DS N 122-94-EF, inciso e), párr. 1, numeral 4), del mismo texto se entiende que se trata de las normas a través de las cuales la SBS exige tales provisiones y no de una exigencia que implique la aprobación de provisiones de cada entidad del sector.

De este modo, tenemos que la deducibilidad de la provisión de cobranza dudosa para el sector objeto de nuestro análisis depende de criterios financieros establecidos por un regulador que no tiene competencia en el ámbito tributario.

\subsection{Regulación de la cobranza dudosa en la legislación comparada}

\subsubsection{España}

En España, el sistema financiero se encuentra supervisado por el Mecanismo Único de Supervisión (MUS), y por el Banco Central de España; a raíz de la última crisis económica y teniendo en cuenta el efecto que el sistema bancario de un país puede tener en otros países, se estableció que todos los países miembros de la Unión Europea, debían tener las mismas reglas, así si bien el Banco Central de España supervisa a las entidades bancarias, la normatividad debe ser acorde a lo establecido por el MUS; sin embargo, lo concerniente a la protección de clientes es competencia de las autoridades nacionales competentes.

De acuerdo a la Circular 4/2017 Anexo 9 del Banco de España (6 de diciembre de 2017), se han establecido dos criterios de clasificación de créditos, uno en función a la insolvencia y otro en función al riesgo país; así, los créditos se clasifican en:

- Riesgo normal.

- Riesgo normal en vigilancia especial.

- Riesgo dudoso.

- Riesgo fallido.

Se permite que cada entidad financiera fije sus propias políticas de cobertura de riesgo, siempre que sean congruentes con lo establecido por el ente supervisor y que la estimación sea prudente, es decir que no contradiga la lógica económica y financiera. 
La metodología implementada por cada entidad debe ser documentada y cualquier modificación sustentada y comunicada al Banco de España.

Las entidades que no cuenten con una metodología propia utilizan el procedimiento alternativo publicado por el Banco de España.

Respecto al procedimiento alternativo, el Banco de España, al establecer los porcentajes de provisión, considera el segmento del crédito, si el mismo se encuentra cubierto con garantías eficaces y la antigüedad de los importes vencidos, siendo así, los porcentajes de provisión se aplican sobre los créditos no cubiertos.

Respecto al reconocimiento de ingresos, la normativa española señala que en el caso de créditos dudosos, los intereses se reconocen como ingresos en función al devengo, sin embargo, deben ser provisionados.

Respecto a los créditos fallidos, entendidos como vencidos, los intereses serán reconocidos como ingresos sólo si son pagados por el deudor, es decir en este caso se aplica el reconocimiento del ingreso en función a lo percibido.

Comparando la normativa española con la peruana, desde el punto de vista financiero, tenemos que la SBS al establecer la calificación de los deudores y los porcentajes de provisión, no ha establecido la posibilidad de que cada entidad tenga una metodología y políticas propias de calificación de deudores y provisión, por el contrario ha adoptado un único procedimiento de evaluación de cartera crediticia.

Los criterios adoptados por la SBS incluyen criterios de tipo de crédito, garantías y antigüedad, sin embargo, establece porcentajes distintos de provisión para la deuda cubierta con garantías y la deuda no cubierta.

Respecto al tratamiento tributario de la provisión por incobrabilidad, en España, la Ley del Impuesto sobre Sociedades, (Ley 27/2014, 2014), en su artículo 13, trata sobre la deducibilidad de las pérdidas por deterioro de los créditos, de manera general, es decir sin hacer ninguna diferenciación o especificación por sectores económicos, y señala que la provisión por deterioro de los créditos es deducible cuando:

- Que haya transcurrido el plazo de 6 meses desde el vencimiento de la obligación.

- Que el deudor esté declarado en situación de concurso.

- Que el deudor esté procesado por el delito de alzamiento de bienes.

- Que las obligaciones hayan sido reclamadas judicialmente o sean objeto de un litigio judicial o procedimiento arbitral de cuya solución dependa su cobro. (p. 96965). 
En el mismo artículo indica que no son deducibles las pérdidas por deterioro de créditos correspondientes a:

- Créditos adeudados por entidades de derecho público, excepto que sean objeto de un procedimiento arbitral o judicial

- Créditos adeudados por personas o entidades vinculadas, salvo que estén en fase de liquidación

- Estimaciones globales del riesgo de insolvencias de clientes y deudores. (p. 96965).

Mediante el capítulo III del Reglamento de la Ley del Impuesto sobre Sociedades (Real Decreto 634/2015, 2015), establece que las entidades financieras que hayan desarrollado una metodología interna, podrán deducir las provisiones específicas que resulten de las metodologías previstas por el Banco de España, sin embargo se efectúan algunas limitaciones como por ejemplo la provisión para estimaciones colectivas tendrá el límite que resulte de aplicar el porcentaje establecido para el método alternativo.

En caso las entidades financieras no hubiesen desarrollado metodologías internas, tienen como límite de deducción los porcentajes establecido por el Banco de España para la metodología alternativa.

Cabe indicar que también se establece casos en los que la provisión por cobertura de créditos no es deducible, como por ejemplo cuando corresponda a operaciones sin riesgo, la parte de la deuda garantizada, la deuda de vinculada, partidos políticos, sindicatos, colegios profesionales, cámaras oficiales excepto se encuentren en etapa concursal.

También se permite la deducción de la provisión genérica que corresponda a operaciones de riesgo normal y riesgo normal en vigilancia especial con el límite del uno por ciento sobre las operaciones que el Banco de España considera, excluyendo las mismas operaciones que para la provisión especifica.

Como se observa, tanto en Perú como en España es aceptable tributariamente la provisión de incobrabilidad determinada según la metodología establecida por el ente supervisor, sin embargo, a diferencia de nuestro país, en España se tiene en el Reglamento un capítulo específico aplicable a las provisiones por riesgo de crédito en entidades financieras y se acepta la deducción de la provisión genérica. Así mismo se hace mención 
expresa a que no es aceptada la provisión de operaciones con vinculadas salvo se encuentren en situación concursal.

\subsubsection{México}

Respecto a la normativa aplicable a la evaluación de la cartera de créditos y al riesgo que implican, la Comisión Nacional Bancaria y de Valores (2015), ha establecido una metodología estándar y permite previa autorización, metodologías internas.

Las metodologías internas, el artículo 2 Bis 70, se basan en sus propias estimaciones y deben incluir parámetros referidos a:

- "Probabilidad de incumplimiento"

- "Severidad de la Pérdida" y

- "Exposición de incumplimiento"

Los deudores se clasifican en cinco categorías de A a D, dependiendo del grado de riesgo del crédito y se requiere, al igual que en Perú, que se efectúen provisiones específicas que identifican al deudor y generales. Sinembargo existen subcategorías dentro de las tres primeras categorías que en Perú no se ven.

En cuanto al método estándar, al igual que en nuestro país los porcentajes de provisión varían dependiendo de la calificación del deudor, tipo de crédito y si las deudas están o no garantizadas.

Tributariamente, el artículo 27 de la Ley del Impuesto sobre la Renta (2016), señala como regla general que son deducibles los gastos "estrictamente indispensables para los fines de la actividad del contribuyente", cuenten con documentación que la sustente y estén contabilizados. Si bien con nuestro país compartimos en algo el carácter de indispensable, los últimos informes de SUNAT (2017a, 2017b) han señalado que no es necesario que los gastos se encuentren registrados contablemente salvo norma expresa y el carácter de indispensable es visto de manera general.

Respecto a la pérdida por incobrables, la fracción XV de la ley mexicana establece como regla general que haya vencido el plazo de prescripción para cobrar o que exista "notoria imposibilidad practica de cobro" tales como haber transcurrido un año desde el vencimiento, existan demandas judiciales o procesos arbitrales, quiebra entre otros. 
Como podemos observar, compartimos algunos de los criterios como es el plazo del año y la existencia de demanda judicial, sin embargo, existen diferencias con la normativa peruana, por ejemplo, en México se señala expresamente que se deben agrupar los diferentes créditos de un deudor a fin de evaluar los requisitos que le corresponden para la deducibilidad de la provisión.

Además, llama nuestra atención que en la Ley de renta se establece que cuando un contribuyente vaya a utilizar la deducción por la deuda incobrable debe comunicarle al deudor a fin de que este registre el ingreso.

En lo relacionado al sector financiero, solo es aceptada la deducción por incobrabilidad cuando la cartera de créditos se castigue según lo establecido por la Comisión Nacional Bancaria de valores, y aquí una evidente diferencia con la Ley de Impuesto a la Renta peruana que es más permisible al señalar que son deducibles todas las provisiones por incobrabilidad que exija el ente regulador del sector financiero.

Cabe resaltar que para castigar una deuda, el ente supervisor de entidades financieras mexicanas exige que exista "evidencia suficiente de que no serán cobrados" (CNBV, s. f., B-6), lo que equivale a decir que tributariamente aceptan la deducción de la provisión por incobrables solo en los casos que se haya determinado la imposibilidad de recuperación de la deuda y se haya castigado la cuenta por cobrar, siendo que la deducibilidad no está en función de las provisiones por cobranza dudosa sino al castigo de las mismas.

\subsubsection{Chile}

La Superintendencia de Bancos e Instituciones Financieras [SBIF] (2018) de Chile ha establecido que el Directorio de cada entidad financiera, es el responsable de que dicha entidad cuente con procedimientos y políticas para la evaluación del riesgo de crédito, "[...] acordes con el tamaño, la naturaleza y la complejidad de sus negocios crediticios." (cap. B-1, punto 1.1., párr. 2), esto es, permite, previa autorización, la utilización de un método interno.

Si bien cada entidad tiene su propia política, la evaluación de "[...] los deudores deben centrarse en su calidad crediticia, [...] también sus créditos en lo que se refiere a garantías, plazos, tasas de interés, moneda, reajustabilidad, etc.” (cap. B-1, punto 2, párr. 2). 
Los deudores son clasificados en tres estados y categorías, y a cada nivel se le asigna un porcentaje de provisión mínimo:

1. Normal, que se subdivide en seis categorías,

2. Subestándar, que se subdivide en cuatro categorías,

3. Incumplimiento, que se subdivide en seis categorías. (cap. B-1, punto 2, párr. 2).

Como vemos en Chile se presentan dieciséis categorías a diferencia que en Perú existen solo cinco categorías o estados y no hay subdivisiones dentro de cada estado, además en el Perú, la SBS ha establecido criterios y procedimientos estándar para la evaluación de la cartera.

Sin embargo, si se comparten algunos criterios de evaluación tales como sector económico al que pertenece, situación del negocio, socios o accionistas, situación financiera y capacidad de pago. Cabe indicar que en Chile se permite una evaluación grupal cuando los montos de deuda son bajos.

Respecto al importe a provisionar, financieramente Chile si deduce o reconoce el valor de las garantías al determinar el monto sobre el cual se provisionará la cartera y exige una provisión mínima de acuerdo al modelo estándar.

En cuanto al reconocimiento de ingresos, en Chile también se suspende el mismo en función al principio de devengo, cuando la cartera, es calificada en las dos últimas categorías de subestándar o en incumplimiento, para reconocerlos en base a lo percibido.

Para el castigo, tanto en Perú como en Chile se establecen criterios financieros basados en que la evaluación de la propia entidad respecto a la recuperación, el ente regulador chileno señala algunos criterios siendo estos enunciativos como por ejemplo plazo de prescripción para demandar el cobro mediante juicio, deuda no garantizada, cantidad de días en situación de vencido, abandono del recupero judicial.

En Chile, tributariamente, de acuerdo al artículo 31 del Decreto Ley 824 (1974), la Ley sobre Impuesto a la Renta, la deducibilidad de un gasto implica que corresponda a un gasto necesario para generar la renta, y que sea acreditado en forma fehaciente.

En relación a la provisión de cobranza dudosa, la normativa tributaria chilena establece como regla general que serán deducibles: “[...] Los créditos incobrables 
castigados durante el año, siempre que hayan sido contabilizados oportunamente y se hayan agotado prudencialmente los medios de cobro.” (Decreto Ley 824, 1974, art. 14).

$\mathrm{Y}$ al igual que en nuestro país menciona un tratamiento tributario distinto en el caso de las instituciones financieras, indicando que serán deducibles las provisiones y castigos que correspondan a la cartera vencida "[...] de acuerdo a las instrucciones que impartan en conjunto la Superintendencia de Bancos e Instituciones Financieras y el Servicio de Impuestos Internos" (Decreto Ley 824, 1974, art. 31).

Sin embargo, a diferencia de lo que ocurre en Perú, en Chile se han establecido restricciones a la deducción tributaria de la provisión exigida por la Superintendencia:

a) La provisión debe corresponder a "créditos clasificados en las dos últimas categorías de riesgo establecidas para la clasificación de cartera, y”

b) El crédito "haya permanecido en alguna de las categorías indicadas a lo menos por el período de un año, desde que se haya pronunciado sobre ella la Superintendencia." (Decreto Ley 824, 1974, art. 31).

Como se aprecia, la normativa chilena de renta, se remite a lo que establezca el ente regulador de entidades financieras, pero con restricciones, buscando una mayor exigencia para la deducción para fines tributarios, disminuyendo las diferencias en el tratamiento tributario con otros sectores económicos que aplican el método general para la deducción de la provisión de cobranza dudosa y los castigos.

Del análisis de la normativa financiera aplicable en los países mencionados en los acápites anteriores, tenemos que aceptan una metodología interna para la provisión de cobranza dudosa basada en estimaciones y tienen otra metodología estándar; en todos ellos buscan adaptar las recomendaciones de Basilea y se proyectan a ser más restrictivos, quizás podríamos decir que rumbo a que exista una sola metodología que permita un mejor control y supervisión en protección de los ahorristas y donde se calcule el riesgo en función a la pérdida esperada y no sólo a la pérdida incurrida; en nuestro país existe solo un método para la evaluación y calificación de la cartera de créditos y con ello se podría afirmar que existe un mejor control de las entidades financieras, inclusive de alguna forma la provisión exigida a las entidades financieras peruanas incluye componentes que miden el riesgo esperado y no el incurrido, tales como el alineamiento y el comportamiento del grupo económico al que pertenecen. 
Tributariamente, vemos que los países analizados son más restrictivos que el nuestro en cuanto a la deducibilidad de la provisión de cobranza dudosa, no siendo suficiente la exigencia del ente regulador del sector económico sino que establecen limitación como por ejemplo que sean deducibles solo en caso sean deudas castigadas o que correspondan a las dos categorías de mayor riesgo crediticio, o que no son deducibles las provisiones de deudas con empresas vinculadas salvo estas últimas se encuentren en concurso o judicial. 


\section{CAPÍTULO III: PRINCIPIOS CONSTITUCIONALES TRIBUTARIOS APLICABLES}

El tratamiento tributario distinto para el Sector financiero respecto a los otros sectores económicos del país debe ser examinado desde la perspectiva de los Principios constitucionales aplicables a la tributación vigente en el Perú.

\subsection{Principio de Igualdad}

De acuerdo al artículo 2 de la Constitución Política del Perú, la Igualdad es un derecho fundamental de las personas, el mismo que obliga al Estado a tratar a todas las personas por igual, por lo que gozan de iguales derechos, sin ninguna discriminación (Rioja, 2013); por tanto, el trato desigual de los iguales se denomina discriminación, el cual está prohibido en la Carta Magna peruana.

\subsubsection{Dimensiones de la Igualdad: formal y material}

La igualdad formal denominada también Igualdad ante la ley y la igualdad material conocida también como la igualdad real.

La igualdad formal es la aplicación directa de la norma constitucional, que como se indicó se trata igual a las personas y no admite ninguna discriminación.

De acuerdo con este rol de la igualdad, las normas jurídicas deben ser aplicadas a todas las personas, sin distinción de ninguna clase. Así los privilegios y cargas que otorga el derecho objetivo deben ser universalmente repartidos entre los sujetos de derechos constitucionales o lo que es lo mismo, los sujetos que se hallen en determinada situación jurídicamente relevante, deben recibir el mismo tratamiento. (Litigios Complejos en Las Américas, s. f., p. 3).

La Dimensión material implica que las personas que se encuentren en condiciones distintas requieran un trato distinto de tal forma que se garantice sus derechos; al existir desigualdades en la sociedad, obliga a adoptar medidas de tal forma que haya oportunidades iguales para ejercer los derechos fundamentales y constitucionales de cada persona; ello se denomina diferenciación. 
Por tanto, tal y como afirma Huerta (2005), se puede concluir lo siguiente:

- "El derecho a la igualdad implica el trato igual entre los iguales".

- "La discriminación implica un trato desigual entre los iguales".

- "La diferenciación implica un trato desigual entre los desiguales". (p. 308).

Entonces debemos abordar la diferencia que existe entre estos dos conceptos: la diferenciación y la discriminación.

De acuerdo al artículo 103 de la Constitución Política del Perú señala que "pueden expedirse leyes especiales porque así lo exige la naturaleza de las cosas pero no por razón de diferencia de las personas" (Rioja, 2013).

Por lo tanto, podemos concluir preliminarmente que la "diferenciación" está constitucionalmente admitida.

Sin embargo, al hablar de "discriminación" implica que estaríamos al frente de un "trato desigual" ello se da cuando no hay justificación ni fundamento en causas de necesidad, idoneidad y proporcionalidad de la norma.

Analizaremos estos conceptos, por lo que debemos partir del principio de Proporcionalidad, el cual es incluido en el artículo 52.1 de la Carta de Derechos Fundamentales de la Unión Europea que señala:

Solo se podrá introducir limitaciones a los derechos fundamentales, respetando el principio de proporcionalidad, cuando sean necesarias y respondan efectivamente a objetivos de interés general reconocidos por la Unión Europea o a la necesidad de protección de los derechos y libertades de los demás. (Parlamento Europeo, 2000, p. 21).

El principio de proporcionalidad está referido a un valor superior de justicia, el cual debe constituir un parámetro constitucional para limitar la actuación de los poderes del Estado en cuanto a los derechos fundamentales de las personas; para ello es necesario aprobar el test de proporcionalidad el cual es un instrumento que ayuda a medir el cuánto se está limitando un derecho fundamental constitucional, dispuesto a través de leyes, por lo cual debe atenderse a la "razonabilidad" y "proporcionalidad" del derecho que está afectando. Este criterio se ha utilizado en frecuente jurisprudencia del Tribunal Constitucional. 
El principio de Proporcionalidad, según afirma Castillo (2005), "exige, a su vez, que la medida limitativa satisfaga los subcriterios de idoneidad, necesidad y proporcionalidad en sentido estricto" (p. 8).

A continuación se desarrollan los subcriterios:

a) Idoneidad: la medida debe ser capaz, adecuada o idónea para conseguir el fin constitucional (adecuación). Es decir, debe evaluarse si la referida medida es idónea para alcanzar la finalidad que se pretende satisfacer ello con sustento constitucional. (pp. 11-12).

b) Necesidad: la medida adoptada debe ser indispensable para lograr el fin legítimo. Es decir, si existe una u otra alternativa que afecta en menor medida el valor, la medida elegida debe ser la que menor sacrificio haga para el derecho intervenido, de lo contrario la medida es inconstitucional. (pp. 12-13).

c) Proporcionalidad: es la relación directamente proporcional entre la afectación y la realización de los bienes constitucionales en colisión (ponderación).

Es decir, debe analizarse si el sacrificio que se producirá en el derecho afectado se encuentra justificado o no en atención al grado de realización del principio que justifica la intervención. Esto permitirá sustentar si nos encontramos ante un supuesto de vulneración de un derecho; para el caso concreto, al derecho de igualdad. (pp. 14-15).

Debemos considerar que los tributos deben aplicarse por igual a las personas que tienen igual posición frente al derecho y los tributos.

\subsubsection{El principio de la Igualdad en la Jurisprudencia}

El Tribunal Constitucional ha señalado que

el reparto de los tributos ha de realizarse de forma tal que se trate igual a los iguales y desigual a los desiguales, por lo que las cargas tributarias directas han de recaer, en principio, donde exista riqueza que pueda ser gravada, lo que evidentemente implica que tenga en consideración la capacidad personal o patrimonial de los contribuyentes. (Sentencia 2727-2002-AA/TC, 2002, fundamento 4, párr. 1). 
Por otro lado, se ha señalado en reiterada jurisprudencia que

"[...] toda persona tiene derecho [...] a la igualdad ante la ley. Nadie debe ser discriminado por motivo de origen, raza, sexo, idioma, religión, opinión, condición económica o de cualquiera otra índole". Contrariamente a lo que pudiera desprenderse de una interpretación literal, estamos frente a un derecho fundamental que no consiste en la facultad de las personas para exigir un trato igual a los demás, sino a ser tratado de igual modo a quienes se encuentran en idéntica situación [...]. La igualdad solamente será vulnerada cuando el trato desigual carezca de una justificación objetiva y razonable. La aplicación pues, del principio de igualdad no excluye el tratamiento desigual; por ello no se vulnera dicho principio cuando se establece una diferencia de trato, siempre que se realice sobre bases objetivas y razonables. (Sentencia 00009-207-PI/TC, 2007, fundamento 20, párr. 1 y 4 ).

Entonces, la interrogante que se desprendería de este principio es: ¿el resto de sectores económicos reciben un trato discriminatorio frente al sector financiero, respecto del tratamiento tributario de la cobranza dudosa? o estamos frente a un trato diferenciado en dicho sector?, la normatividad tributaria aplicable en el sector financiero, ¿cumple el test de proporcionalidad?

De acuerdo al análisis estamos frente a un trato diferenciado, dado que el sector financiero es un contribuyente igual al resto de empresas de otros sectores económicos, sin embargo, para efectos tributarios tiene tratamiento distinto con ventajas tributarias respecto a las provisiones de cobranza dudosa, dado que se rige por las normas de la SBS los cuales son propuestas globales sin individualizar a cada cliente con morosidad en cada Entidad Financiera. Sin embargo, el resto de sectores económicos deben cumplir con los requisitos exigidos en la Ley del Impuesto a la Renta y del Reglamento, respecto a cada cliente en forma individualizada; el cual genera muchas veces contingencias tributarias respecto al sector financiero que tiene largamente ventajas tributarias en el aspecto tratado.

Por lo tanto, el tratamiento diferenciado si afecta el principio de igualdad, dado que no existe sustento en la normatividad tributaria ni exposición de motivos las razones por las que el sector financiero tienen un tratamiento distinto para deducir las provisiones de cobranza dudosa; aun peor no se evidencia la aplicación del test de proporcionalidad. 
De lo expuesto concluimos que no se justifica el tratamiento diferenciado en el sector bancario y financiero respecto a los otros sectores económicos; por lo que analizaremos en el capítulo IV, los otros factores que podrían o no justificar esta situación.

\subsection{Principio de Capacidad Contributiva}

El principio de capacidad contributiva se define en la actualidad como indica Bravo (2011): "la idoneidad de un sujeto para hacer frente a las cargas tributarias, expresada en diversas manifestaciones de riqueza". Es decir, este principio supone la aptitud de las personas para pagar los tributos, lo cual implica, poseer la riqueza suficiente para poder cumplir con las obligaciones tributarias.

El principio de capacidad contributiva supone que las personas deben pagar los tributos en razón de su capacidad económica, o sea en base a la disposición de su riqueza.

Asimismo, este principio busca que las personas participen en el gasto público en razón a sus posibilidades, y limita al Estado de no ejercer de forma arbitraria su poder tributario.

En el punto anterior hemos analizado el principio de igualdad, y se puede afirmar, tal y como indica el jurista César Landa, que

todos los ciudadanos están obligados a concurrir en el sostenimiento de las cargas públicas, pero ello no supone que todos deben, efectivamente, pagar los tributos, sino que deben hacerlo aquellos ciudadanos en base a los principios constitucionales y de las leyes que rigen en la sociedad, y que tengan la capacidad contributiva en base a los hechos tipificados por la ley, es decir, que para tributar debe existir la capacidad contributiva. (Como se citó en Novoa, 2006, p. 103).

"En el Perú, la doctrina nacional es unánime al afirmar que la Constitución Política de la Nación consagra en su artículo 74 de manera implícita el principio de capacidad contributiva al recoger los principios de igualdad y no confiscatoriedad." (Novoa, 2006, p. 103).

El principio de capacidad contributiva "es acogido como un límite material de tributación, como una exigencia de personalización económica del impuesto, encontrándose como tal consagrado de forma directa o indirecta, en la mayoría de los textos constitucionales." (Celorico Palma, 2000, p. 9). 
Por ejemplo, en la Constitución Española (1978) sí señala expresamente este principio, en su artículo 31 "Todos contribuirán al sostenimiento de los gastos públicos de acuerdo con su capacidad económica mediante un sistema tributario justo inspirado en los principios de igualdad y progresividad que, en ningún caso, tendrá alcance confiscatorio". (punto 1).

Esta precisión es interesante, dado que ayuda a limitar el poder tributario del Estado tomando en cuenta el principio de capacidad contributiva vinculado a la igualdad, progresividad y no confiscatoriedad.

\subsubsection{El principio de capacidad contributiva en la Jurisprudencia}

Tal como se ha indicado en párrafos anteriores,

no existe en el texto de la Constitución Política del Perú, un reconocimiento expreso al principio de capacidad contributiva, sin embargo, el Tribunal Constitucional ha reconocido su carácter implícito, indicando que deriva del principio de igualdad ello se desarrolla en las Sentencia 0033-2004-AI/TC, [...] Sentencia 1907-2003-AA/TC, [...] Sentencia 0033-2004-AI/TC) y [...] STC 00053-2004-AI/T aplicable a los impuestos, tasas y contribuciones. (Bravo, 2009, p. 225).

Por lo expuesto pasaremos a remitirnos al Anexo $\mathrm{N}^{\circ} 1$ a fin de analizar la capacidad contributiva del sector.

Se verifica que el sector de intermediación tiene una participación en la recaudación total de $9.20 \%$ y $9.45 \%$ en los años 2017 y 2018 respectivamente; porcentaje importante en la estadística mostrada; frente a otros sectores económicos que tienen una menor participación en la recaudación y por tanto una menor capacidad contributiva tales como: Minería, Hidrocarburos, Manufactura de productos primarios, Servicios de energía eléctrica, Transporte y Construcción vemos que las empresas de menor capacidad contributiva respecto a las entidades Bancarias y Financieras, tienen el tratamiento tributario de la Ley del Impuesto a la Renta, con la exigencia de cumplir dichos requisitos para que proceda la deducción tributaria para efectos del Impuesto a la Renta anual.

Cabe indicar que las empresas de energía eléctrica prestan servicios masivos, con cantidad de clientes probablemente mucho mayor a las entidades bancarias, con menor 
capacidad contributiva como se demuestra, pero con un tratamiento diferenciado con el que no estamos de acuerdo.

Este análisis valida nuestro argumento que la capacidad contributiva tampoco justifica el tratamiento diferenciado en el sector de intermediación financiera.

Por tanto, concluido el análisis de los dos principios tributarios, se puede inferir que la forma de deducción exclusiva que tiene el sector financiero y bancario no se justificaría por el lado de los principios de Igualdad y capacidad contributiva.

En el siguiente capítulo abordaremos otras razones justificadas distintas a las expuestas, que validarían el tratamiento diferenciado de la deducción de provisiones de cobranza dudosa para efectos tributarios en las entidades financieras, desde el punto de vista del desarrollo económico y crecimiento del país, dado que al parecer habría una relación directa positiva entre el crecimiento de la economía peruana con el crecimiento del sistema financiero. 


\section{CAPITULO IV: PROVISIÓN DE COBRANZA DUDOSA. COMPARACIÓN DEL TRATAMIENTO TRIBUTARIO ENTRE EL SECTOR FINANCIERO Y OTROS SECTORES ECONÓMICOS}

Para determinar la deducibilidad de la provisión de cobranza dudosa en empresas de sectores económicos distintos al financiero, el legislador ha establecido reglas que permiten verificar la incobrabilidad de la deuda y desconocer la provisión en caso no guarde relación con los criterios esbozados en el acápite 2.1.

Sin embargo, en el caso de entidades del sistema financiero es diferente porque tributariamente se aceptan las provisiones ordenadas por la SBS, a excepción de las provisiones genéricas.

Exceptuando la deducción de la provisión genérica lo que nos dice el legislador es que las provisiones por riesgo crediticio de un deudor calificado como normal no son deducibles, esto incluye las provisiones pro cíclicas, ${ }^{1}$ y estamos de acuerdo con ello, si no hay un riesgo de recuperabilidad no tiene sentido desde un punto de vista económico afectar los resultados con dicha provisión.

Antes de continuar debemos resaltar que los objetivos regulatorios de la Superintendencia de Banca y Seguros son ajenos a los fines tributarios, mientras que los primeros buscan proteger al ahorrista, los segundos buscan gravar la capacidad contributiva de los contribuyentes, basada en hechos económicos reales.

\subsection{Razones que validan el procedimiento establecido por la SBS a la provisión de cobranza dudosa de instituciones financieras}

De acuerdo a lo desarrollado en el capítulo I del presente estudio, la exigencia de una provisión de cobranza dudosa en las Instituciones Financieras tiene un trasfondo económico importante, el cual se evidencia en:

\footnotetext{
${ }^{1}$ Medida que hace que a la tasa de provisión correspondiente a la categoría Normal se añada un componente adicional. La Superintendencia comunicará su activación.
} 
- El efecto que una crisis económica tiene en la Banca y como, más aun con la globalización, el mismo afecta a otros países, así lo reconoce el Comité de Basilea habiéndose concretado acuerdos importantes para fortalecer la Banca, tal como lo señala el Porporatto (2013), “en el marco del Comité de Basilea de Supervisión Bancaria se han concretado los principales acuerdos para fortalecer las normas internacionales de los sistemas bancarios y así reducir el riesgo de contagio desde el sector financiero hacia la economía real" (p. 14).

- La correlación que existe entre el crecimiento del PBI y el desarrollo de las entidades financieras, al respecto Bustamante Romaní (2006) concluye que "el sistema financiero es importante para el crecimiento económico de largo plazo, y que medidas para su represión desaceleran tal crecimiento" (diapositiva 66).

- Considerando la función de intermediación que realizan las entidades financieras, tenemos que estas captan fondos provenientes del ahorro de las familias, empresas e inversionistas, y por ello se deben establecer normas de protección y recupero de ese ahorro; así la finalidad de establecer provisiones para cubrir el riesgo crediticio, debe verse no solo como una afectación a resultados sino como mayores exigencias de capital para hacer frente a contingencias en el recupero de colocaciones que a su vez brinde confianza a los ahorristas.

Por lo expuesto, son razones económicas las que validan el tratamiento tributario diferenciado de la deducción de la provisión de cobranza dudosa para las empresas del sector financiero y se relacionan con el crecimiento del país. Bustamante Romaní (2006) "ha demostrado que para el caso peruano la causalidad es en ambos sentidos es decir el crecimiento de la economía afecta positivamente al desarrollo del sistema financiero y viceversa." (diapositiva 66). 


\subsection{Argumentos en contra del tratamiento diferenciado}

\subsubsection{Evaluación de cartera: alineamiento y conglomerado único}

Existen procedimientos adoptados por la SBS que evidencian tratamientos distintos, respecto a otros sectores económicos, en cuanto a cómo se mide el riesgo de recupero y se establece la provisión por incobrabilidad, nos referimos al llamado "alineamiento" y al "riesgo único".

Respecto al alineamiento, llama nuestra atención, que tributariamente se acepte una provisión mayor a la categoría que le correspondiera si solo se evaluara la relación cliente banco, ¿a qué nos referimos? De acuerdo a los lineamientos de evaluación de cartera, las instituciones financieras deben alinear la categoría asignada a su cliente proveniente de su evaluación y de la relación directa que tiene con este, a la categoría de mayor riesgo que posea en otra entidad si la deuda en esta otra entidad representa por lo menos el $20 \%$ de la deuda en el sistema financiero; ello implica que se reconozca como provisión, gasto, un mayor importe al que correspondiera si solo se evaluara la relación cliente-banco. Claro está que en otros sectores, no es posible que la relación crediticia de un cliente con un tercero influya en la provisión de cobranza dudosa deducible tributariamente.

En cuanto al "riesgo único" nuestra reflexión va en el mismo sentido, ¿hasta qué punto el pertenecer a un grupo económico o conglomerado financiero, puede o debe influenciar en la calificación de un cliente y esa calificación tener efecto tributario?, si bien distinguir dicho efecto es subjetivo, conceptualmente podría estar trasladándose el riesgo de un deudor a otro.

\subsubsection{Intereses en suspenso, ¿percibido o devengado?}

Uno de los efectos de la calificación de un deudor, es la suspensión del reconocimiento de los intereses como ingreso, así la SBS establece que los intereses, comisiones y gastos relacionados con créditos vencidos, en cobranza judicial o clasificados como dudoso o perdida, no se reconocen en cuentas de resultados sino se mantienen en suspenso hasta que efectivamente se cobren.

En este aspecto, también podría creerse que existen diferencias con otros sectores económicos, quienes, para el reconocimiento de ingresos aplican el principio del devengado. 
Analizaremos lo ocurrido antes de la modificación del artículo 57 (Decreto Legislativo $\left.\mathrm{N}^{\circ} 979,2007\right)$ de la Ley de Impuesto a la Renta.

Hasta antes de la modificación mencionada en el párrafo anterior, la Administración Tributaria, observó durante sus fiscalizaciones a entidades financieras, los intereses en suspenso y determinó que los mismos debían gravarse con el Impuesto a la renta ya que habían devengado, desconociendo la practica contable establecida por la SBS; según Villanueva Gonzales (octubre 2008), el reconocimiento como ingreso de los intereses en suspenso en función al transcurso del tiempo, fue una posición errada, tanto de la Administración Tributaria como del Tribunal Fiscal (p. 88).

El artículo 57 de la Ley, hasta el 31 de diciembre de 2018 se fundamenta en el principio del devengado, pero no lo define, motivo por el cual, nos remitimos al concepto contable. Para Villanueva Gonzales (octubre 2008), devengado no significa reconocer automáticamente los ingresos, sino que debe evaluarse la posibilidad que los ingresos fluyan a la empresa (p. 83).

El marco conceptual del Consejo de Normas Internacionales de Contabilidad en su párrafo 4.48, señala que solo debe reconocerse ingresos si pueden ser medidos con fiabilidad y además exista un grado de certidumbre suficiente que los mismos fluirán a la empresa (p. 24). Considerando ello, tenemos que la Ley de Impuesto a la Renta al adoptar el principio de devengado está reconociendo que podrían existir situaciones en las que las empresas no reconozcan ingresos.

La cuestión es, si la SBS dentro de sus normas contables adoptó el principio de devengado, no era necesario que exprese que en caso de deudas vencidas en judicial, los intereses generados no debían ser reconocidos como ingresos sino como intereses en suspenso.

Ahora bien, si la Administración y el Tribunal Fiscal hubieran aplicado el principio de devengado de acuerdo a las normas contables, debieron analizar si había posibilidad de que los intereses en suspenso fluyan a las instituciones financieras; sin embargo, considerando el procedimiento utilizado para evaluar la cartera de créditos y calcular las provisiones de incobrabilidad, no en todos los casos había riesgo en el ingreso por intereses.

Por ejemplo, en el caso de un cliente en categoría dudoso corresponde una provisión del $50 \%$, eso significa que había riesgo solo de 50\%, por tanto por el otro $50 \%$ 
era posible reconocer los intereses como ingreso; que la Administración grave el 50\% de los intereses no registrados como ingresos, significa aplicar el principio de devengado de forma adecuada.

Así, cuando el legislador incluye la modificación del artículo 57 de la Ley Impuesto a la Renta, indicando que los intereses en suspenso se reconocerán como ingreso en función a lo percibido y no a lo devengado, incluyó un principio distinto al devengo, siendo esto también una diferencia con lo que aplican otros sectores económicos.

Cabe resaltar que la Sentencia Casación N 12304 - 2014, respecto a intereses en suspenso, señaló entre otros que jurídicamente, no es posible que la normativa emitida por la Superintendencia de Banca y Seguros, modifique disposiciones de carácter estrictamente tributario, toda vez que en materia de Derecho Tributario rige los principios de legalidad y reserva de ley tributaria previstos en el artículo 74 de la Constitución Política del Perú, según los cuales, en sentido general, "los tributos se crean, modifican o derogan, o se establece una exoneración, exclusivamente por ley o decreto legislativo en caso de delegación de facultades." (Rioja, 2013).

Ahora bien, a partir del 01 de enero de 2019, se encuentra vigente la modificación del artículo 57 de la Ley de Impuesto a la Renta a través del Decreto Legislativo $N^{\circ} 1425$ (2018), el cual incluyó un concepto de devengo aplicable tributariamente:

se entiende que los ingresos se devengan cuando se han producido los hechos sustanciales para su generación, siempre que el derecho a obtenerlos no esté sujeto a una condición suspensiva, independientemente de la oportunidad en que se cobren y aun cuando no se hubieren fijado los términos precisos para su pago. No obstante, cuando la contraprestación o parte de esta se fije en función de un hecho o evento que se producirá en el futuro, el ingreso se devenga cuando dicho hecho o evento ocurra. (p. 41).

Respecto al reconocimiento de los intereses relacionados a deudas vencidas se mantiene su reconocimiento en función de lo percibido, manteniéndose la diferencia con el tratamiento tributario de los otros sectores económicos.

Cabe indicar que en otros sectores económicos se registra los ingresos provenientes de deudas vencidas y se efectúa la provisión de cobranza dudosa que corresponda, siendo claro el tratamiento diferenciado. 


\subsubsection{Castigo de cuentas provisionadas}

Los sectores económicos distintos al financiero, tienen sus propias políticas contables y procedimientos para el castigo de una cuenta por cobrar, sin embargo, para que sea aceptado tributariamente, el requisito es que se demuestre la incobrabilidad mediante via judicial.

Para que el castigo de créditos incobrables, sea aceptado tributariamente sólo deben cumplir el requisito de exhibir la constancia de irrecuperabilidad que emite la Superintendencia de Banco y Seguros.

$\mathrm{Al}$ respecto, nuestro cuestionamiento linda con los procedimientos que exige la SBS para tal fin en comparación con los requisitos que se exigen a los otros sectores económicos.

Como vemos, lo descrito aunado al deber de contribuir y al principio de igualdad evidenciaría desde nuestro punto de vista, una diferenciación injusta o sin asidero tributario, donde el ente supervisor, SBS, sin competencia tributaria, finalmente es el que en realidad dicta requisitos tributarios para la deducción de la provisión de cobranza dudosa, aceptando tributariamente provisiones financieras lo que es impensable para otros sectores económicos.

\subsubsection{Comparación con empresa de servicio masivo}

Confrontaremos el tratamiento tributario diferenciado de la deducción de la cobranza dudosa en dos tipos de empresas, una dedicada a telecomunicaciones y las del sector financiero, las que tienen en común: el servicio masivo a usuarios o clientes y que tienen miles de clientes a nivel nacional con sucursales y centros de atención en distintas ciudades del Perú; situaciones y características similares en estas empresas.

A continuación, mencionaremos un caso de una Empresa de Telecomunicaciones (en adelante ET) con más de 300,000 clientes con deudas vencidas y provisionadas en su contabilidad y deducidas para efectos del Impuesto a la Renta.

La posición tributaria respecto al reparo provisión de cobranza dudosa, tanto de parte de la SUNAT (2016) y del Tribunal Fiscal (s. f.-a, s. f.-b) fueron confirmados. 
Pasaremos a detallar los argumentos que invocó la empresa ET para acreditar la morosidad de los clientes deudores, señalados en la Resolución del Tribunal Fiscal $\mathrm{N}^{\circ}$ 17044-8-2010 (2010), como sigue:

1. Gestiones de Cobranza: Los medios que utilizó ET para acreditar son:

a) Sistema llamador: son locuciones grabadas que solicitan el pago al cliente. Presentó a SUNAT en medio magnético un backup.

b) Telegestión: Es efectuada por terceros por empresas de call center a través de llamadas, cartas enviadas a clientes.

c) Notificación de deuda anterior mediante recibo: ET se amparó en la RTF 1657-4-2007, Carta de OSIPTEL y ley 28870 que califican este procedimiento como "gestión de cobranza".

d) Corte parcial y total: Estos cortes están guardados en los sistemas informáticos de ET; señaló que es una forma de exigir al deudor que regularice su pago para que el servicio sea reinstalado.

e) Notificaciones de Baja: ET notificó cartas a clientes comunicando la deuda impaga e indicando al pie, que si no efectúa el pago hasta determinada fecha se le dará de baja como usuario del servicio.

f) Cobranza pre judicial y gestión judicial: ET encargó a terceros la gestión de cobro a estudios de abogados expertos en cobranzas. Presentó reportes varios, donde se consigna el nombre del cliente deudor, acciones realizadas y en la mayoría el monto de la deuda; no se consignan el número del comprobante de pago o recibos que adeuda cada uno de los clientes.

g) Facturas de gestores pre-judicial y empresas de mensajería: ET no presentó documentación vinculada a la gestión de cobranza de las deudas provisionadas. Las facturas de estos proveedores presentadas solo acredita las cobranzas recuperadas.

h) Invitaciones a financiamiento: ET presentó algunas de ellas para acreditar su existencia, sin vincularlas con las provisiones contabilizadas.

i) Envío a Central de Riesgo (INFORCORP): Este tipo de cobranza es denominada por el contribuyente como Cobranza Blanca, que consiste en que después de haberse producido la baja del servicio, ET remite a INFOCORP información de clientes morosos para su inclusión en la base de datos del Sistema Consolidado de Morosidad- SICOM. 
j) Cartas de cobranza a principales clientes: cartas enviadas a clientes.

2. Análisis de crédito en forma individual por cliente: ET señala que el solo hecho de llevar el control por cliente en sus sistemas informáticos constituye un análisis periódico; determina la morosidad a partir de los 120 días de atraso.

3. Identificación y anotación contable de las cuentas cobranza dudosa: ET invocó la aplicación de la RTF $N^{\circ}$ 1317-1-2005 en el que señala que debe detallarse en forma discriminada por cliente y puede constar en un anexo al Libro y legalizado. También invocó la RTF Nº 01657-4-2007 el cual considera cumplido el requisito de la norma, cuando el contribuyente presenta el Libro de Inventario y Balance y en hojas sueltas legalizadas constando la identificación de cada cliente, número de comprobante de pago e importe de la deuda provisionada.

El Tribunal Fiscal concluyó que la empresa ET no acreditó las gestiones de cobranzas señaladas en las normas del Impuesto a la Renta; no acreditó haber realizado las llamadas a sus clientes dado que no existe registro ni grabación de las llamadas realizadas por el call center contratado.

Por otro lado señaló que el artículo 5 de la Ley 28870 (2006) que modifica el artículo 34 de la Ley 26338, invocado por la empresa ET, solo aplica para actividades de saneamiento; en cuanto a la suspensión del servicio señaló que este hecho es una suspensión de la prestación de servicios y no representa gestión de cobro ya que el usuario puede contratar a otro operador y no pagar la deuda a ET; en cuanto a los reportes informáticos señaló el Tribunal Fiscal que en ella no se identifica al cliente, la deuda, comprobante ni monto que permita conciliar con el monto provisionado por cobranza dudosa (no existe coincidencia).

En cuanto a las empresas gestoras de los cobros contratadas por ET, no presentó documentación que demuestre que hayan efectuado acciones de cobranza, posición confirmada en la RTF $N^{\circ}$ 2976-2-2004 en el que indica que las constancias presentadas por las empresas encargadas de las cobranzas extrajudiciales al no estar acompañadas de documentos que respalde sus actos efectuados, corresponde el reparo.

Adicionalmente el Tribunal Fiscal señaló que la información remitida a INFOCORP no demostró que dichas deudas correspondan a las provisionadas en su contabilidad; tampoco se aceptan las cartas de cobranza presentadas dado que ET no 
acreditó que éstas hayan sido recepcionadas por los clientes; además del hecho de indicar que en caso haya efectuado el pago, el cliente debía acreditarlo ante ET

Respecto a las dificultades financieras de los clientes de ET mediante el análisis periódico, el Tribunal Fiscal señaló que estos análisis no reflejan gestiones de cobranzas ni grado de morosidad del deudor.

En cuanto al anexo detallado del Libro de Inventario y Balance, este fue legalizado un año posterior al ejercicio cerrado materia de fiscalización, con lo que se evidencia que la impresión del anexo ha podido realizarse entre el 31 de diciembre del 2000 y la fecha de legalización. Respecto a la RTF 1317-1-2005 invocada por ET, este no resulta aplicable, dado que en dicho caso el contribuyente si había acreditado los requisitos de la norma para la deducción de la provisión de cobranza dudosa, por ello se le aceptó la legalización posterior de los anexos al Libro de Inventario y Balance; situación que no ha ocurrido con la empresa ET.

Por lo tanto, al haber incluido como gasto la provisión de cobranza dudosa de deudas de clientes con antigüedad de 120 días (menor a 12 meses) y al no demostrar el riesgo de incobrabilidad de la deuda y la no discriminación de las cuentas de cobranza dudosa en el Libro de Inventario y Balance al cierre del Ejercicio, corresponde mantener el reparo efectuado por la Administración Tributaria.

Hemos analizado los argumentos legales tributarios de una empresa dedicada a los servicios masivos de Telefonía que cuenta con miles de clientes a nivel nacional y que tuvo en el año fiscalizado por la SUNAT, más de 300,000 clientes con deudas de morosidad contabilizadas y provisionadas en sus cuentas de gastos que afectaron a resultados y que los dedujo para efectos del cálculo del Impuesto a la Renta; asimismo se ha detallado la posición del Tribunal Fiscal que confirmó el reparo de la provisiones de cobranza dudosa observadas por la SUNAT por falta del cumplimiento de los requisitos señalados expresamente en el artículo 37 inciso i) de la Ley del Impuesto a la Renta (DS $\left.\mathrm{N}^{\circ} 179-2004-E F, 2004\right)$ y el artículo $21^{\circ}$ inciso f) del Reglamento del Impuesto a la Renta (DS N $\left.{ }^{\circ} 122-94-E F\right)$.

Tal como se ha expuesto en capítulos anteriores, las disposiciones del Impuesto a la Renta en cuanto a los requisitos de provisionar la cobranza dudosa no le son aplicables al sector Bancos y Financieras; sin embargo, se le aplica al resto de sectores económicos; con la jurisprudencia citada se puede concluir que para las empresas de servicios masivos 
se requiere sustentar tributariamente, para cada uno de los clientes con deuda impaga, lo siguiente:

- La gestión de cobranza debe constar en documentación escrita, entregadas por la empresa y recepcionadas por el deudor personalmente, también puede ser a través de llamadas telefónicas y otros medios: correo electrónico, mensaje de texto y otros, siempre que la empresa fiscalizada acredite documentariamente ante la SUNAT que haya realizado estas acciones.

- La Administración Tributaria (SUNAT) no admite como prueba de gestión de cobranza los Recibos de Pago con la indicación de la deuda anterior pues ésta no implica que se está realizando una cobranza expresa por parte del prestador del servicio.

- El solo hecho de presentar el Libro de Inventario y Balances ${ }^{2}$ con el detalle de los nombres de clientes identificados, numero de comprobante de pago, fecha de vencimiento, monto de la deuda ya sea dentro del Libro o en hojas anexas legalizadas no basta para tener derecho a su deducción.

Si bien es un requisito formal es constitutivo de derecho a su deducción pero deben cumplirse los otros requisitos de la norma de Renta (requisitos sustanciales) para que en conjunto tenga la empresa fiscalizada el derecho a su deducción para efectos de la determinación del Impuesto a la Renta del Ejercicio gravable fiscalizado.

Por otro lado, tenemos en el Perú el sector Intermediación Financiera (Bancos y Financieras), que brindan también servicios masivos dado que también cuenta con miles de clientes a nivel nacional; sin embargo, ellos aplican el artículo 37 inciso h) de la Ley del Impuesto a la Renta (DS N ${ }^{\circ}$ 179-2004-EF, 2004), en donde se acepta la deducción para efectos del impuesto, de aquellas provisiones ordenadas por la Superintendencia de Banca y Seguros (SBS).

Entonces hemos confrontado el tratamiento tributario diferenciado de la deducción de la Cobranza dudosa en dos tipos de empresas que tienen en común: el servicio masivo a usuarios o clientes y que tienen miles de clientes a nivel nacional con

\footnotetext{
${ }^{2}$ Es un requisito formal de la norma aplicable para la deducción de la Provisión de cobranza dudosa; explicada en el capítulo II del presente trabajo.
} 
Sucursales y centros de atención en distintas ciudades del Perú, por tanto existen situaciones y características similares en estas empresas; sin embargo, se verifica la diferenciación de tratamiento tributario en las provisiones de cobranza dudosa que existe en ambos sectores (Intermediación Financiera y Telecomunicaciones).

A la empresa ET con más de 300,000 clientes con deudas morosas, se le ha exigido el cumplimiento cabal de las normas generales ya citadas que regulan el tratamiento de cobranza dudosa por cada uno de sus clientes que forman parte de la provisión deducida; sin embargo, a una entidad Bancaria y Financiera se le aplica las normas de la SBS quien ordena los montos de las provisiones.

Tal como se ha señalado en el capítulo II del presente trabajo de Investigación, las provisiones ordenadas por la SBS son generales y de cumplimiento obligatorio para las entidades bancarias y financieras que pertenecen al sector de intermediación financiera, por lo que la forma de determinar las provisiones de cobranza dudosa se basan en objetivos financieros que buscan la protección al ahorrista, e incluyen parámetros de morosidad esperada y no necesariamente es la incurrida y real como sucede en los otros sectores económicos para fines tributarios.

Esos montos estimados y determinados por la SBS nacen para fines estrictamente financieros, sin embargo dicho procedimiento es aceptado para fines tributarios de manera discriminatoria; sin exigencia documentaria de acreditación para dicho calculo, por tanto procede para la SUNAT su deducción tributaria de la forma como lo determina la SBS, estando muy lejos de la forma que debe hacerlo el resto de sectores económicos en cuanto a su acreditación documentaria pese a que podríamos encontrar situaciones o condiciones similares.

Haciendo un análisis de la contribución a la recaudación de ingresos derivados para el Estado de cada sector económico, concretamente, respecto de los Tributos Internos, vemos en el Anexo $\mathrm{N}^{\circ}$, que la recaudación del sector de intermediación financiera representa en los años 2017 y 2018 el $9.21 \%$ y $9.45 \%$ respectivamente del total de ingresos recaudados por la SUNAT de Tributos Internos.

Los ingresos del sector telecomunicaciones en los años 2017 y 2018 son el $2.37 \%$ y $2.34 \%$; entonces, vemos que en el caso expuesto, la empresa ET pertenece al sector de telecomunicaciones y se evidencia que esta tiene una menor capacidad contributiva que los bancos, probablemente tenga un mayor número de clientes respecto a las entidades 
bancarias y financieras, sin embargo se le exige al sector de telecomunicaciones (y otros) el cumplimiento de requisitos señalados en la norma de la Ley del Impuesto a la Renta por cada cliente para la deducción de la cobranza dudosa.

Somos de la posición que existe una diferenciación de tratamiento tributario muy injusto, al que tiene mayor capacidad contributiva se le exige solamente la aprobación de la SBS para contabilizar las provisiones, teniendo SUNAT un papel de mero observador que exista dicha aprobación, sin poder cuestionar el procedimiento y acreditación documentaria.

Esta diferenciación crea ventajas tributarias en este aspecto para el sector de intermediación financiera, dado que deduce importes de cobranza dudosa de origen financiero y que tributariamente le son aceptadas.

\subsection{Nuestra posición}

Teniendo en cuenta que nuestro país, se encuentra en desarrollo, que busca incrementar el PBI y la importancia del sector financiero para ese fin, se justificaría la existencia de un tratamiento tributario diferenciado.

La adopción por parte de la SBS de las recomendaciones del Comité de Basilea, respecto a medir los riesgos crediticios en función a la pérdida esperada y no a la pérdida incurrida, implicaría que tributariamente se acepte la deducibilidad de estimaciones, ya que como mencionamos en el capítulo I, la dificultad de información para medir la pérdida esperada tendría como efecto una evaluación de riesgo plasmada de subjetividades.

Por otro lado, la complejidad, dinamismo y globalización de la actividad financiera conlleva a que una crisis en ese sector tenga consecuencias macroeconómicas en un país y la misma se extienda a otros países, allí radica la importancia del sector y el motivo por el cual la normativa tributaria permite la deducción de las provisiones por incobrabilidad exigidas financieramente.

Por ejemplo la crisis del 2008 que se inició con el boom inmobiliario en los Estados Unidos de Norte America, el exceso de créditos a personas sin evaluar adecuadamente su capacidad de pago, bajas tasas de interés, la falta de control y supervisión financiera adecuada, conllevó a que los deudores no pudiesen pagar sus 
créditos, las aseguradoras tuvieron que hacer frente a ello, el gobierno americano apoyó a las aseguradoras con dinero de los contribuyentes, se generó desconfianza en el sector financiero, inclusive entre empresas del mismos sector, las empresas tenían dificultades para obtener crédito, afectando las exportaciones e importaciones, aumentó el desempleo, aumentó el gasto público; así "la crisis de la economía financiera se convirtió en una crisis de la economía real" (Tanzi, 2010).

La gran tarea en el ámbito tributario, es buscar la neutralidad, es decir, un equilibrio entre no afectar el desarrollo económico y que las entidades financieras tributen de una forma distinta respecto a los otros sectores económicos. Además, no se debe perder el control tributario, por el contrario, debiera modificarse y evolucionar conforme avanzan o surgen nuevas operaciones financieras, por ello, la regulación debe ser revisada constantemente a fin de evitar posibilidades de elusión, evasión o planificaciones fiscales agresivas.

Si bien pareciera "injusto" el tratamiento tributario aplicable a las entidades financieras, respecto de la provisión de cobranza dudosa y que el mismo no se alinea con el cumplimiento de los principios tributarios, la contribución de las entidades financieras a la recaudación y los intereses de los ciudadanos se ponen por encima bajo el mecanismo regulatorio de Evaluación y Clasificación del Deudor y la Exigencia de Provisiones, establecido por la SBS, a pesar de no ser un ente tributario, incluso la propia ley del impuesto a la renta recoge este tratamiento lo que valida esta premisa de poner por encima el interés público en aras de mantener el equilibrio del mercado y de los ahorristas y por lo tanto contribuir en el crecimiento económico en el Perú.

Cabe precisar que si bien en la norma peruana no existe una definición expresa del significado de interés público; sin embargo, tenemos en la Sentencia N 0090-2004AA/TC (2004), a partir del fundamento 10 que:

10. La doctrina acepta la existencia de conceptos con contenido y extensión variable; esto es, reconoce la presencia jurídica de conceptos determinables por medio del razonamiento jurídico que, empero, varían de contenido y extensión según el contexto en que se encuentren o vayan a ser utilizados.

11. El interés público tiene que ver con aquello que beneficia a todos; por ende, es sinónimo y equivalente al interés general de la comunidad. Su satisfacción constituye uno de los fines del Estado y justifica la existencia de la organización administrativa. 
De lo anterior se confirma nuestra posición que, a pesar de que en apariencia el tratamiento diferenciado en el sector financiero va en contra de los principios tributarios como igualdad y el implícito de capacidad contributiva, el interés público está por encima de todo ello, el cual justifica este tratamiento distinto en el sector financiero. 


\section{CONCLUSIONES}

- Las recomendaciones del Comité de Basilea, buscan minimizar los riesgos a los que se exponen las instituciones financieras, y son adoptadas por muchos países inclusive por el nuestro. Entre ellas señala que la supervisión es un elemento fortalecedor que promueve la eficiencia y estabilidad macroeconómica de un país.

- Tanto Basilea como la NIIF 9 proponen, en lo concerniente al riesgo crediticio, que la estimación de la provisión por insolvencia (provisión por incobrabilidad) se realice en función a las pérdidas esperadas y no a las pérdidas incurridas, y así dar información confiable a los stakeholders

- En países como España, México y Chile, la regulación tributaria, se remite a la regulación emitida por el ente supervisor del sector financiero de sus respectivos países, sin embargo, establecen restricciones en cuanto a su deducibilidad.

- En nuestro país, el tratamiento tributario diferenciado aplicable al sector financiero, no se justificaría por el lado de los principios de Igualdad y capacidad contributiva.

- El tratamiento tributario diferenciado para el sector financiero se fundamenta y justifica en razones económicas, dado que existe una relación directa entre el crecimiento del PBI y el desarrollo de dicho sector, para el caso peruano la causalidad es en ambos sentidos es decir el crecimiento de la economía afecta positivamente al desarrollo del sistema financiero y viceversa.

- Si bien en el mundo se viene adoptando la NIIF 9 y las recomendaciones de Basilea buscan que las provisiones reflejen las pérdidas esperadas y no las incurridas, se debe considerar que el objetivo financiero es distinto al tributario, por ello cuando la SBS obligue la aplicación de la NIIF 9, el efecto de su adopción no debiera tener efectos tributarios.

- Sabiendo de la complejidad y especialidad del sector financiero, se debería evaluar la posibilidad de implementar una metodología tributaria especial para la provisión de cobranza dudosa para el sector financiero, la que podría darse vía reglamentaria.

- El Estado peruano prioriza el interés de los ciudadanos y la contribución a la recaudación, así, en aras de mantener el equilibrio del mercado y de los ahorristas 
y el crecimiento económico en el Perú, la ley del impuesto a la renta se remite al tratamiento regulatorio establecido por la SBS a efectos de la deducibilidad de la provisión de cobranza dudosa.

- Considerando que todos tenemos el deber de contribuir y con la finalidad de equiparar en algo la diferenciación tributaria frente a otros sectores económicos, se deben establecer restricciones a la deducibilidad tributaria de la provisión de cobranza dudosa para el sector financiero:

- Eliminar el procedimiento de alineamiento con efecto tributario.

- Eliminar el efecto del conglomerado único, para efectos tributarios teniendo en cuenta que en nuestro país no se tributa por grupo económico.

- Restringir la deducibilidad de la provisión por incobrable a los deudores con mayor riesgo, esto es a los deudores calificados como dudosos o Perdida. 


\section{REFERENCIAS}

Alva Matteucci, M. (15 de mayo de 2017). ¿Cuándo procede la provisión de cobranza dudosa?: a propósito de la dificultad de pagos en las zonas declaradas en emergencia [mensaje en un blog]. Recuperado de http://blog.pucp.edu.pe/blog/blogdemarioalva/2017/05/15/cuando-procede-laprovision-de-cobranza-dudosa-a-proposito-de-la-dificultad-de-pagos-en-laszonas-declaradas-en-emergencia/

Aparicio, C. y Moreno, H. (2011). Calidad de la cartera crediticia bancaria y el ciclo económico: una mirada al gasto en provisiones bancarias en el Perú (2001-2011) (DT/03/2011. SBS Documentos de Trabajo). Recuperado de http://www.sbs.gob.pe/Portals/0/jer/ddt_ano2011/3_Aparicio_y_Moreno_2011. pdf

Banco de España. (6 de diciembre de 2017). Circular 4/2017, de 27 de noviembre, del Banco de España, a entidades de crédito, sobre normas de información financiera pública y reservada, y modelos de estados financieros. Boletín Oficial del Estado [BOE]. Recuperado de https://www.boe.es/boe/dias/2017/12/06/pdfs/BOE-A2017-14334.pdf

Bravo, J. (2009). Breves reflexiones sobre el desarrollo jurisprudencial del principio de capacidad contributiva. Revista Ius Et Veritas, (38), 222-227. Recuperado de http://revistas.pucp.edu.pe/index.php/iusetveritas/article/view/12202/12767

Bravo, J. (2011). El principio de capacidad contributiva desde la perspectiva del Tribunal Constitucional. En F. Iannacone, C. García, P. Carrasco (coord.), Estudios de derecho constitucional tributario (pp. 639-647). Lima, Perú: Universidad de San Martín de Porres.

Bustamante Romaní, R. (2006). Desarrollo Financiero y Crecimiento Económico en el Perú [diapositivas de PowerPoint]. Recuperado de http://www.bcrp.gob.pe/docs/Proyeccion-Institucional/Seminarios/Conferencia12-2006/Conf_0612_05-Bustamante.pdf?cv=1

Castillo, L. (2005). El principio de proporcionalidad en la jurisprudencia del Tribunal Constitucional peruano. Revista Peruana de Derecho Público, 6(11), 127-151. Recuperado de https://pirhua.udep.edu.pe/bitstream/handle/11042/1908/Principio_proporcionali dad_jurisprudencia_Tribunal_Constitucional_peruano.pdf?sequence=1\&isAllow ed $=\mathrm{y}$

Celorico Palma, C. (2000). La evolución conceptual del principio de capacidad contributiva [Conferencia Técnica]. Recuperado del sitio de internet del Centro Interamericano de Administraciones Tributarias [CIAT]: https://www.ciat.org/Biblioteca/ConferenciasTecnicas/2000/Espanol/Taormina italia_sicilia_2000_tema1_2_portugal.pdf 
Centro Interamericano de Administraciones Tributarias [CIAT]. (2017). Curso sobre Control a Instituciones y Operaciones Financieras [versión en PDF]. Recuperado de http://capacitacion.ciat.org

Comisión Nacional Bancaria y de Valores [CNBV]. (s. f.). Anexo 33. Serie A. Criterios relativos al esquema general de la contabilidad para instituciones de crédito. Recuperado de https://www.cnbv.gob.mx/Anexos/Anexo\%2033\%20CUB.pdf

Comisión Nacional Bancaria y de Valores [CNBV]. (2015). Disposiciones de carácter general aplicables a las Instituciones de Crédito. Recuperado de http://www2.congreso.gob.pe/sicr/cendocbib/con4_uibd.nsf/D8DF59524F8CB9 9105257F1800565EFB/\$FILE/Disposiciones_de_car\%C3\%A1cter_general_apli cables_a_las_instituciones_de_cr\%C3\%A9dito.pdf

Comisión Nacional Bancaria y de Valores [CNBV]. (2018). Guía de Autorización, para los sectores de Instituciones de Crédito y Entidades y Organismos de Formento. Recuperado de https://www.gob.mx/cms/uploads/attachment/file/354337/Guia_Riesgo_de_Cre dito_27-julio18.pdf

Consejo de Normas Internacionales de Contabilidad. (2010). El Marco Conceptual para la Información Financiera. Recuperado de https://www.mef.gob.pe/contenidos/conta_publ/con_nor_co/vigentes/nic/ES_G VT_BV2017_conceptual.pdf

Constitución Española. (1978). Artículo N³1. Congreso de los Diputados. Recuperado de

http://www.congreso.es/consti/constitucion/indice/titulos/articulos.jsp?ini=31\&ti $\mathrm{po}=2$

De Miguel Domínguez, J., Miranda Torrado, F., Pallas González, J. y Peraza Fandiño, C. (2003). La medición del riesgo de crédito y el nuevo acuerdo de capital del Comité de Basilea. Santiago de Compostela, España: Universidad de Santiago de Compostela. Facultad de Ciencias Económicas y Empresariales.

Decreto Legislativo $\mathrm{N}^{\circ}$ 979, Modifican el Texto Único Ordenado de la Ley del Impuesto a la Renta aprobado por el Decreto Supremo $\mathrm{N}^{\circ} 179-2004-\mathrm{EF}$ y normas modificatorias. (15 de marzo de 2007). Recuperado del sitio de internet del Congreso de la República del Perú: http://www.leyes.congreso.gob.pe/Documentos/DecretosLegislativos/00979.pdf

Decreto Legislativo $\mathrm{N}^{\circ} 1425$, Decreto Legislativo que modifica la Ley del Impuesto a la Renta. (13 de septiembre de 2018). Recuperado del sitio de internet de El Peruano: https://busquedas.elperuano.pe/download/url/decreto-legislativo-que-modificala-ley-del-impuesto-a-la-re-decreto-legislativo-n-1425-1691026-14

Decreto Ley 824, Aprueba texto que indica de la Ley sobre Impuesto a la Renta. (31 de diciembre de 1974). Última versión 6 de febrero de 2019. Recuperado del sitio de internet de la Biblioteca del Congreso Nacional de Chile: https://www.leychile.cl/Navegar?idNorma=6368 
Decreto Supremo N ${ }^{\circ}$ 122-94-EF, Reglamento de la Ley del Impuesto a la Renta. (19 de septiembre de 1994). Recuperado del sitio de internet de la Superintendencia Nacional de Aduanas y de Administración Tributaria: http://www.sunat.gob.pe/legislacion/renta/reglamento.html\#

Decreto Supremo $\mathrm{N}^{\circ}$ 179-2004-EF, Texto Único Ordenado de la Ley del Impuesto a la Renta. (6 de diciembre de 2004). Recuperado del sitio de internet de la Superintendencia Nacional de Aduanas y de Administración Tributaria: http://www.sunat.gob.pe/legislacion/renta/ley/

Deloitte. (2017). Regulación bancaria en México: en camino hacia los estándares internacionales. Recuperado de https://www2.deloitte.com/content/dam/Deloitte/mx/Documents/financialservices/2017/Folleto_Regulacion_Bancaria_2017.pdf

Gutiérrez, S., Osorio, H. y Romero-Meza, R. (2018). NIIF 9(IFRS 9) Instrumentos Financieros: Aplicación Práctica para Determinación de Pérdida Esperada de Carteras de Activos Financieros. Recuperado de http://www.pkfchile.cl/media/10041827/paper-acad\%C3\%A9mico-niif-9aplicaciones-pr\%C3\%A1cticas.pdf

Huerta, L. (2005). El derecho a la igualdad. Pensamiento Constitucional, 11(11), 307334. http://revistas.pucp.edu.pe/index.php/pensamientoconstitucional/article/view/76 $86 / 7932$

Instituto Mexicano de Contadores Públicos. (2017). Ley del Impuesto Sobre la Renta 2017. Texto y comentarios [versión en PDF]. Recuperado de http://imcp.org.mx/wp-content/uploads/2017/04/ISR-2017.pdf

Izu Kanashiro, J. (2018). Implementación en el Perú de los estándares internacionales de Basilea referidos a la participación de la deuda subordinada como componente del capital bancario (Tesis para optar al grado de Magíster en Derecho Internacional Económico). Recuperada de http://tesis.pucp.edu.pe/repositorio/bitstream/handle/20.500.12404/10215/IZU_ KANASHIRO_IMPLEMENTACION_EN_EL_PERU_DE_LOS_ESTANDAR ES_INTERNACIONALES_DE_BASILEA.pdf?sequence=1\&isAllowed=y

Landa, C. (2006). Los principios tributarios en la Constitución de 1993: una perspectiva constitucional. En Temas de derecho tributario y derecho público. Lima, Perú: Palestra Editores.

Ley 27/2014, de 27 de noviembre, del Impuesto sobre Sociedades. (27 de noviembre de 2014). Recuperado del sitio de internet del Boletín Oficial del Estado de España [BOE]: https://www.boe.es/boe/dias/2014/11/28/pdfs/BOE-A-2014-12328.pdf

Ley de Instituciones de Crédito, Nueva Ley publicada en el Diario Oficial de la Federación el 18 de julio de 1990, D. F., México. Última reforma publicada DOF 22-06-2018. Recuperada de http://www.diputados.gob.mx/LeyesBiblio/pdf/43_220618.pdf 
Ley del Impuesto sobre la Renta, Nueva Ley publicada en el Diario Oficial de la Federación el 11 de diciembre de 2013, D. F., México. Última reforma DOF 3011-2016. Recuperada http://www.diputados.gob.mx/LeyesBiblio/pdf/LISR_301116.pdf

Ley $N^{\circ} 26702$, Ley General del Sistema Financiero y del Sistema de Seguros y Orgánica de la Superintendencia de Banca y Seguros. (6 de diciembre de 1996). Recuperado de http://www2.congreso.gob.pe/sicr/cendocbib/con4_uibd.nsf/8CEF5E01E937E7 6105257A0700610870/\$FILE/26702.pdf

Ley $\mathrm{N}^{\circ} 28870$, Ley para optimizar la gestión de las entidades prestadoras de servicios de saneamiento. (12 de agosto de 2006). Recuperado del sitio de internet de la Superintendencia Nacional de Servicios de Saneamiento: https://www.sunass.gob.pe/doc/normas\%20legales/128870.pdf

Litigios Complejos en Las Américas. (s. f.). Derecho a la igualdad y a la no discriminación. Recuperado http://litigioscomplejos.com/tematicos/igualdad/6/6_2_1.pdf

Mundo Contable. (12 de junio de 2012). La provisión de cobranza dudosa ¿cuándo efectuarla? [mensaje en un blog]. Recuperado de http://mundocontableperu.blogspot.com/2012/06/la-provision-de-cobranzadudosa-cuando.html

Muñoz, J. (1999). Calidad de la cartera del sistema bancario y el ciclo económico: una aproximación econométrica para el caso peruano. Revista Estudios Económicos, (4), 107-118. Recuperado http://www.bcrp.gob.pe/docs/Publicaciones/Revista-EstudiosEconomicos/04/Estudios-Economicos-4-5.pdf

Novoa, G. (2006). El Principio de la Capacidad Contributiva. Revista Derecho \& Sociedad, (27), 101-106. Recuperado de http://revistas.pucp.edu.pe/index.php/derechoysociedad/article/viewFile/17169/1 7458

OSIPTEL. (s. f.). Quiénes somos. Recuperado de https://www.osiptel.gob.pe/categoria/quienessomos

Parlamento Europeo, Consejo de Europa y Comisión Europea. (2000). Carta de los Derechos Fundamentales de la Unión Europea. Diario Oficial de las Comunidades Europeas. Recuperada de http://www.europarl.europa.eu/charter/pdf/text_es.pdf

Porporatto, P. (2013). Estudio sobre el tratamiento tributario y el control de las instituciones financieras en América Latina [versión en PDF]. Recuperado de https://www.taxcompact.net/documents/ITC_2013-05_Estudio-sobre-elTratamiento-Tributario-en-LA.pdf

Real Decreto 634/2015, de 10 de julio, por el que se aprueba el Reglamento del Impuesto sobre Sociedades. (10 de julio de 2015). Recuperado del sitio de internet del 
Boletín Oficial del Estado de España [BOE]: https://www.boe.es/boe/dias/2015/07/11/pdfs/BOE-A-2015-7771.pdf

Resolución $\mathrm{N}^{\circ}$ 17044-8-2010 (Lima). (2010). Tribunal Fiscal. Recuperado del sitio de internet del Tribunal Fiscal: http://www.mef.gob.pe/contenidos/tribu_fisc/Tribunal_Fiscal/PDFS/2010/8/201 0_8_17044.pdf

Rioja, A. (2013). Constitución Política del Perú de 1993. Lima: Jurista Editores.

Sentencia 00009-2007-PI/TC (Lima). (2007). Pleno Jurisdiccional del Tribunal Constitucional. Recuperado del sitio de internet del Tribunal Constitucional: https://www.tc.gob.pe/jurisprudencia/2007/00009-2007-AI\%2000010-2007AI.html

Sentencia N 0090-2004-AA/TC (Lima). (2004). Tribunal Constitucional. Recuperado del sitio de internet del Tribunal Constitucional: https://www.tc.gob.pe/jurisprudencia/2004/00090-2004-AA.html

Sentencia N ${ }^{\circ}$ 2727-2002-AA/TC (Lima). (2002). Tribunal Constitucional. Recuperado del sitio de internet del Tribunal Constitucional: https://tc.gob.pe/jurisprudencia/2004/02727-2002-AA.pdf

Superintendencia de Banca, Seguros y AFP [SBS]. (2008). Resolución S.B.S. N $N^{\circ} 11356-$ 2008. http://www.sbs.gob.pe/Portals/0/jer/pfrpv_normatividad/20160719_Res-113562008.pdf

Superintendencia de Banca, Seguros y AFP [SBS]. (2016). Resolución S.B.S. $N^{\circ} 975-$ 2016. https://intranet2.sbs.gob.pe/intranet/INT_CN/DV_INT_CN/1630/v1.0/Adjuntos/ 975-2016.r.pdf

Superintendencia de Bancos e Instituciones Financieras Chile [SBIF]. (2018). Compendio de Normas Contables. Recuperado de https://www.sbif.cl/sbifweb3/internet/archivos/norma_6545_1.pdf

Superintendencia Nacional de Aduanas y de Administración Tributaria [SUNAT]. (s. f.). Cuadro A 18. Ingreso Tributario Anual recaudado por la SUNAT - Tributos Internos según actividad económica [cuadro Excel]. Recuperado de http://www.sunat.gob.pe/estadisticasestudios/nota_tributaria/cdro_A18.xls

Superintendencia Nacional de Aduanas y de Administración Tributaria [SUNAT]. (2016). ¿Quiénes somos? Recuperado de http://www.sunat.gob.pe/institucional/quienessomos/index.html

Superintendencia Nacional de Aduanas y de Administración Tributaria [SUNAT]. (2017a). Informe $N^{\circ}$ 004-2017-SUNAT/5D0000. Recuperado de http://www.sunat.gob.pe/legislacion/oficios/2017/informe-oficios/i004-2017.pdf 
Superintendencia Nacional de Aduanas y de Administración Tributaria [SUNAT]. (2017b). Informe $N^{\circ}$ 005/2017-SUNAT/5D0000. Recuperado de http://www.sunat.gob.pe/legislacion/oficios/2017/informe-oficios/i005-2017.pdf

Tanzi, V. (noviembre-diciembre 2010). La crisis financiera y económica de 2008-2009: Efectos fiscales y monetarios. Revista Internacional de Presupuesto PúblicoASIP, XXXVIII(74). Recuperado de http://t9000176.ferozo.com/la-crisisfinanciera-y-economica-de-2008-2009-efectos-fiscales-y-monetarios/

Tribunal Fiscal. (s. f.-a). Procedimientos tributarios. Recuperado de https://www.mef.gob.pe/contenidos/tribu_fisc/tripticos/001612.pdf

Tribunal Fiscal. (s. f.-b). ¿Qué es? Recuperado de https://www.mef.gob.pe/es/informacion-institucional/ique-es

Ustáriz González, L. (junio 2003). El Comité de Basilea y la supervisión bancaria. Vniversitas, (105), 431-462. Recuperado de http://www.redalyc.org/pdf/825/82510517.pdf

Villanueva Gonzales, M. (octubre 2008). Intereses en suspenso: ¿capítulo final o un nuevo comienzo? Revista del Instituto Peruano de Derecho Tributario [IPDT], (47), 81-98. Recuperado de http://www.ipdt.org/uploads/docs/05_Rev47_MVG.pdf

Zavaleta Álvarez, M. (2010). El problema de aplicar la "Fórmula del peso" (ponderación) en los límites al poder tributario: a propósito del mal entendimiento de la "solidaridad-deber de contribuir" en el Perú. Vox Juris, (19), 103-120. Recuperado de http://www.derecho.usmp.edu.pe/biblioteca/vox_jurix/Vox_Juris_N19.pdf

Zurita González, J., Martínez Pérez, J. y Rodríguez Montoya, F. (septiembre-octubre 2009). La crisis financiera y económica del 2008. Origen y consecuencias en los Estados Unidos y México. El Cotidiano, (157), 17-27. Recuperado de https://www.redalyc.org/pdf/325/32512739003.pdf 


\section{BIBLIOGRAFÍA}

Arrieta, J. (2011). Derecho tributario y fuentes. Perspectiva española. En R. Rojas y F. Vega (coord.), Derecho tributario peruano y español: un análisis comparado de problemas comunes (pp. 17-44). Lima, Perú: Universidad de San Martín de Porres. Facultad de Derecho.

Asociación de Bancos del Perú [Asbanc]. Departamento de Estudios Económicos. (22 de agosto de 2016). Nivel de endeudamiento de los hogares en el Perú. Asbanc Semanal, 6(209). Recuperado de https://www.asbanc.com.pe/Publicaciones/ASBANC\%20Semanal\%20209\%20$\%$ 20Endeudamiento.pdf

Banco Central de Reserva del Perú [BCRP]. (2002). El costo del crédito en el Perú. Recuperado de http://www.bcrp.gob.pe/docs/Publicaciones/Documentos-deTrabajo/2006/Costo-del-credito-en-Peru-2002.pdf

Banco de Pagos Internacionales. (2010). Basilea III: Marco internacional para la medición, normalización y seguimiento del riesgo de liquidez [versión PDF]. Recuperado de https://www.bis.org/publ/bcbs188_es.pdf

Banco de Pagos Internacionales. (2014). Revisión del Método Estándar para el riesgo del crédito [versión en PDF]. Recuperado de https://www.bis.org/bcbs/publ/d307_es.pdf

Becerra, B., Ramírez, M. y Rejas, M. (2016). Valorización de empresa MiBanco, Banco de la Microempresa (Trabajo de investigación para optar al Grado de Magíster en Finanzas). Recuperada de http://repositorio.up.edu.pe/bitstream/handle/11354/1200/Bruno_Tesis_maestria _2016.pdf? sequence $=1 \&$ isAllowed $=\mathrm{y}$

Bernales, E. (1999). La Constitución de 1993. Análisis Comparado [versión PDF]. Recuperado

de http://www2.congreso.gob.pe/sicr/cendocbib/con3_uibd.nsf/DD60BF7FE0882E E3052578ED00705992/\$FILE/Const.Comentada_Bernales_Indice_R\%C3\%A9 gimenEcon\%C3\%B3mico.pdf

Choy, M., Costa, E. y Churata, E. (2015). Radiografía del costo del crédito en el Perú (DT. N ${ }^{\circ}$ 2015-001. Serie de Documentos de Trabajo. Mayo 2015). Recuperado de http://suscripciones.bcrp.gob.pe/docs/Publicaciones/Documentos-deTrabajo/2015/documento-de-trabajo-01-2015.pdf

Comité Latinoamericano Tributario [COLATRI] y Federación Latinoamericana de Bancos [FELABAN]. (2014). Fiscalidad comparada de ventas de cartera castigada sin sustentos tributarios en el sector bancario y en ejercicio diferentes. Recuperado de http://felaban.s3-website-us-west2.amazonaws.com/noticias/archivo20150417163616PM.pdf 
Cornejo, A., Lizana, C. y Pérez, M. (2005). Riesgo operacional en las entidades bancarias chilenas y Nuevo Acuerdo Basilea II (Seminario para optar al título de Ingeniero en Información y Control de Gestión, Universidad de Chile, Chile). Recuperado de http://repositorio.uchile.cl/bitstream/handle/2250/142181/Riesgo\%20operaciona $1 \% 20$ en $\% 20$ las $\% 20$ entidades $\% 20$ bancarias $\% 20$ chilenas $\% 20 \ldots$ pdf? sequence $=1$ \&isAllowed=y

Corredor Alejo, O. (Jul.-Ago. 2013). Deducción de la provisión de cartera en el sector financiero. Legis, (178), 21-24. Recuperado de http://legal.legis.com.co/document/Index?obra=rimpuestos\&document=rimpuest os_e3c97b9acea800d0e0430a01015100d0

Faúndez Ugalde, A. (2013). Gasto Tributario por Intereses Pagados o Devengados en Operaciones de Crédito Análisis de Jurisprudencia. Revista Estudios Tributarios, (8), 203-232. Recuperado de http://repositorio.uchile.cl/bitstream/handle/2250/138175/Antonio_Faundez.pdf? sequence $=1 \&$ isAllowed $=\mathrm{y}$

Jiménez Sotelo, R. (10 de junio de 2008). El Comité de Basilea y sus principios básicos [mensaje en un blog]. Recuperado de http://blog.pucp.edu.pe/blog/renzojimenez/2008/06/10/el-comite-de-basilea-ysus-principios-basicos/

Krugman, P. y Wells, R. (2014). Macroeconomía (2a ed.). Barcelona, España: Reverté.

Menéndez, Á. (2019). Encuesta sobre Préstamos Bancarios en España: enero de 2019 (Boletín Económico 1/2019. Artículos Analíticos). Recuperado de https://www.bde.es/f/webbde/SES/Secciones/Publicaciones/InformesBoletinesR evistas/ArticulosAnaliticos/19/T1/descargar/Fich/be1901-art2.pdf 
ANEXOS 


\section{Anexo 1: Ingreso tributario anual recaudado por la SUNAT}

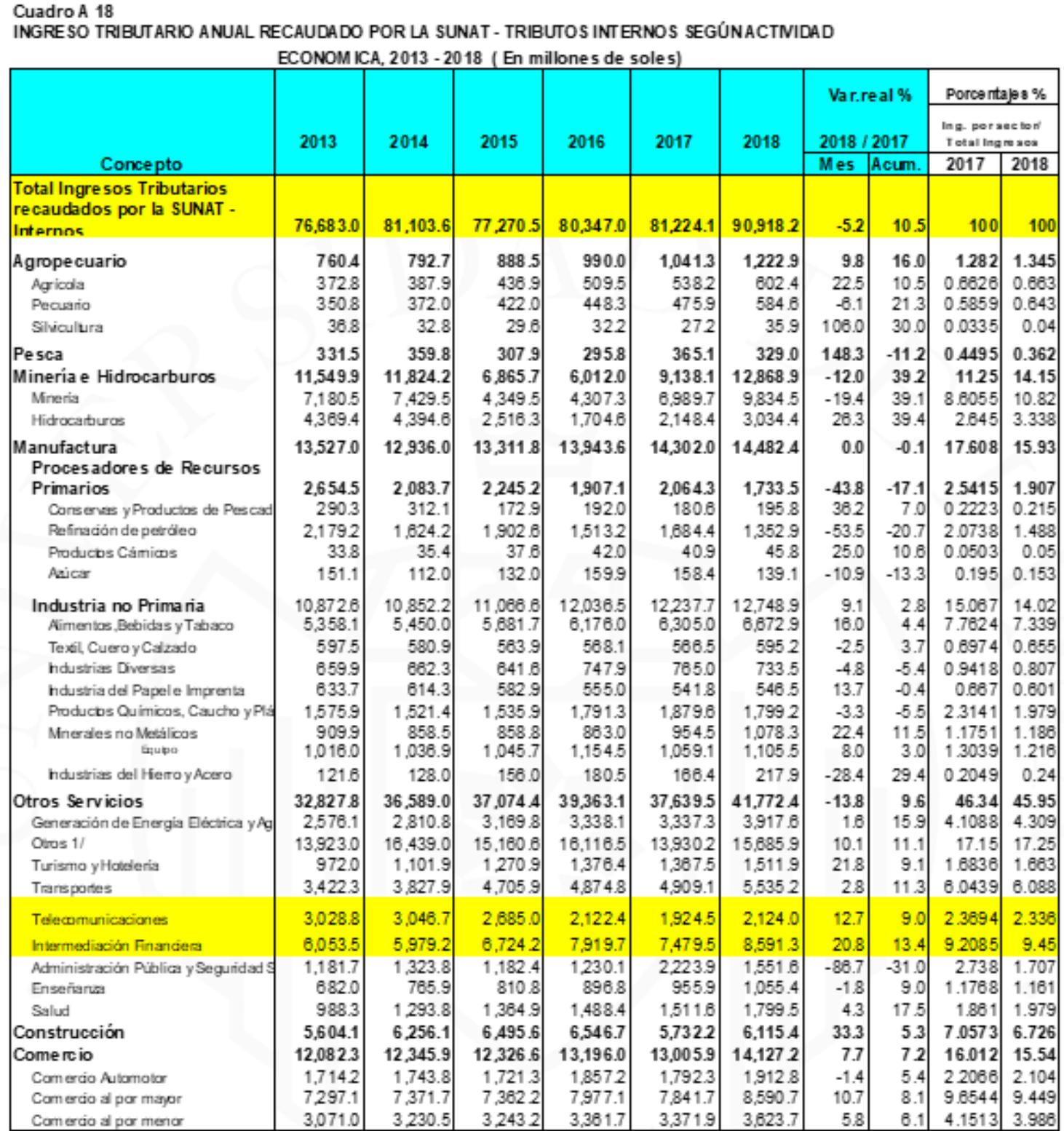

Fuente: SUNAT (s. f.) 